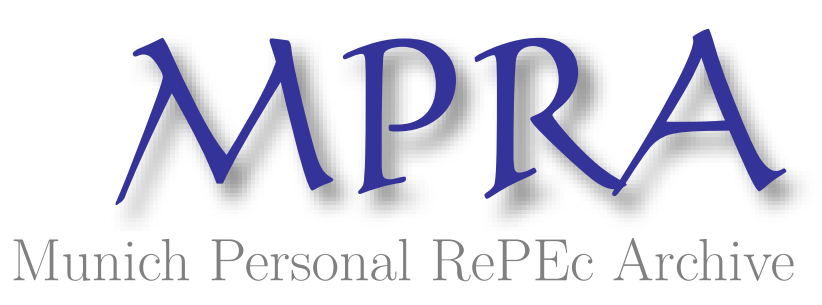

\title{
Transactional Sex as a Response to Risk in Western Kenya
}

Robinson, Jonathan and Yeh, Ethan

UC Santa Cruz

26 February 2008

Online at https://mpra.ub.uni-muenchen.de/7405/

MPRA Paper No. 7405, posted 28 Oct 2008 06:33 UTC 


\title{
Transactional Sex as a Response to Risk in Western Kenya*
}

\author{
Jonathan Robinson $^{\dagger}$ \\ University of California, Santa Cruz \\ Ethan $\mathrm{Yeh}^{\ddagger}$ \\ McKinsey and Company
}

February 26, 2008

\begin{abstract}
Formal and informal commercial sex work is a way of life for many poor women in developing countries. Though sex workers have long been identified as crucial in affecting the spread of HIV/AIDS, particularly in sub-Saharan Africa, the nature of sex-for-money transactions remains poorly understood. Using a unique panel dataset constructed from 192 self-reported sex worker diaries which include detailed information on sexual behavior, labor supply, and income shocks, we find that sex workers adjust their supply of risky, better compensated sex to cope with unexpected income shocks, exposing themselves to increased risk of HIV infection. In particular, women are $3.2 \%$ more likely to see a client, $21.7 \%$ more likely to have anal sex, and $20.6 \%$ more likely to have unprotected sex on days in which a household member falls ill. Women also increase their supply of risky sex on days after missing work due to STI symptoms. Given that HIV prevalance has been estimated at $9.8 \%$ in this part of Kenya, these behavioral responses entail significant health risks for sex workers and their partners, and suggests that sex workers are unable to cope with income risk through other formal or informal consumption smoothing mechanisms.
\end{abstract}

${ }^{*}$ We are grateful to Orley Ashenfelter, David Card, Kenneth Chay, Raj Chetty, Damien de Walque, Esther Duflo, Pascaline Dupas, David Evans, Julian Jamison, Michael Kremer, David Lee, Ethan Ligon, Carol Medlin, Edward Miguel, Christina Paxson, and Ann Swidler for their generous advice and support. We also wish to thank seminar, conference, and lunch participants at ASHE, Berkeley, NEUDC, Princeton, and the Conference on Infectious Diseases in Poor Countries at Cornell for helpful comments. We thank the Strengthening STD/HIV Control Project in Kenya and the University of Nairobi Institute for Tropical and Infectious Disease for their collaboration. This project would not have been possible without the help of Chester Morris, Benson Estambale, Frank Plummer, Michael Bryant, Lorenzo Casaburi, Katie Conn, Willa Friedman, Anthony Keats, and Paul Wang. Eva Kaplan provided superlative research assistance, and Nathaniel Wamkoya and Eric Obila did excellent work cleaning and entering the data. We thank all the peer educators in Busia, Kenya for their cooperation throughout. Above all, we thank Violet Kanyanga and Carolyne Kemunto for their tireless efforts from start to finish. This project was supported by grants from the Princeton University Industrial Relations Section, the UCSF-UCB Exploratory Center in Behavioral Economic Epidemiology, the UCB Center for African Studies, the UCB Institute of Business and Economic Research, the UCB Center for International and Development Economics Research, and the US Environmental Protection Agency (EPA) under the Science to Achieve Results (STAR) Graduate Fellowship Program. EPA has not officially endorsed this publication and the views expressed herein may not reflect the views of the EPA. All errors are our own.

${ }^{\dagger}$ Department of Economics, University of California, Santa Cruz, e-mail: jmrtwo@ucsc.edu

${ }^{\ddagger}$ McKinsey and Company, 5 Houston Center, 1401 McKinney, 26th floor, Houston, TX 77010, e-mail: ethan_yeh@mckinsey.com 


\section{Introduction}

Exchanging sex for money, goods, or services is a way of life for many poor women in developing countries, yet little is understood about the way that the commercial or transactional sex market functions. While commercial sex workers (CSWs) have long been identified as critical in affecting the spread of the HIV/AIDS epidemic (UNAIDS, 2002; Hawken et al., 2002; Hudson, 1996; Plummer et al., 1991), comparatively little work has gone beyond characterizing sex workers as a high-risk subpopulation.

Even estimating the number of women engaged in transactional sex is notoriously difficult. This is particularly true in sub-Saharan Africa, where transactional sex is present within many types of sexual relationships, including long-term partnerships and even marriage (Swidler and Watkins, 2007; Caldwell et al., 1989; Luke, 2006; Schoepf, 2004; Hunter, 2002; Wojcicki, 2002a). In Kenya, $14.5 \%$ of men and $5.5 \%$ of women aged 15-49 report having ever engaged in transactional sex, a figure which is likely an underestimate given the sensitive nature of the question (Central Bureau of Statistics, 2004). In this context, commercial sex work might be thought of as one extreme along a continuum of sexual relationships that feature a transactional component, with either "dating" or monogamous marriage at the other extreme. In this study, we identified 1,205 formal and informal sex workers in Busia, Kenya, a peri-urban town in Western Kenya. This amounts to roughly $11.6 \%$ of the population of Busia women aged 15-49.

This paper utilizes a unique panel dataset constructed from 192 daily sex worker diaries to analyze how sex workers decide whether to engage in unprotected sex with clients. The diaries included questions on income, expenditures, transfers given and received, and, most importantly, the specific sexual services provided to each client, the amounts paid for these services, and whether they used a condom for each sex act. In total, the dataset includes information on 18,894 transactions over 12,432 sex worker days.

We study sex workers' decisions in an intertemporal framework, and estimate how the supply of unprotected sex is affected by health shocks. We find compelling evidence that women increase their supply of risky, better compensated sex in response to short-term income shocks at home. Women are $3.2 \%$ more likely to see a client, $21.7 \%$ more likely to have anal sex, and $20.6 \%$ more likely to engage in unprotected sex on days in which another household member (typically 
a child) falls ill. Similar responses are observed on days just after a woman recovers from the symptoms of an STI (which arguably might be seen as an exogenous shock to her ability to supply sex). Women do this in order to capture the roughly 38 Kenyan shilling (US \$0.54) premium for unprotected sex and the 74 shilling (US \$1.06) premium to anal sex.

Our results are related to a number of other studies of risk-coping mechanisms in poor countries, especially since the women we study make up a sizeable fraction of the population of adult women in the area. Like most people in developing countries, the women in our sample lack access to formal credit or savings, and the informal risk coping mechanisms that are typically available to sex workers (such as informal insurance systems of gifts and loans between friends and family) have consistently been shown by other authors to be inefficient in insuring risk (i.e., Townsend, 1994; Paxson, 1992; Gertler and Gruber, 2002). The increase in transactional sex we find is similar to the labor supply effect documented by, for instance, Kochar $(1995,1999)$, though the increase in labor supply we find here is of independent interest because it comes at such a high cost: HIV prevalence has been estimated at 9.8\% in Busia District (Central Bureau of Statistics, 2004). Over time, the increases in risky sex that we observe here have enormous health consequences for these women, their sexual partners, and society as a whole as HIV is passed on to the general population. These results are all the more striking because we focus on daily income shocks, rather than larger shocks such as annual or seasonal agricultural fluctuations.

This paper is one of the few studies to identify and document specific costs to inefficient consumption smoothing, beyond consumption fluctuations themselves. Other examples include Rosenzweig and Wolpin (1993), who argue that Indian farmers are forced to use productive assets (bullocks) to smooth consumption, incurring substantial reductions in long-term productivity in the process, and Jacoby and Skoufias (1997), who find that Indian households pull their children out of school to work on the farm when shocks occur, which may reduce the long-term earnings potential of their children. Our study also highlights the difference between income smoothing and consumption smoothing, as discussed in Morduch (1995). Empirically, consumption by the women in our sample is insensitive to health shocks, so that standard tests would conclude that women are well-insured against these shocks. Such tests do not explicitly account for how 
consumption smoothing is achieved, which in this case involves a significant health cost. ${ }^{1}$

The results of this study also have important implications for understanding the spread of HIV/AIDS, and in designing interventions to limit its spread. In sub-Saharan Africa, the risk of HIV/AIDS infection is enormous for both formal and informal sex workers. Among formal sex workers, the HIV/AIDS prevalence rate has been estimated to be as high as 25 to 75 percent (National AIDS Control Council [Kenya], 2005; UNAIDS, 2004; Morison et al., 2001). The risks are similarly large for women that supply transactional sex more casually. Dunkle et al. (2004) estimated that informal sex workers in South Africa were $54 \%$ more likely to be HIV positive than other women. Research on concurrent partners in sub-Saharan Africa also suggests that these women may have a similar or even greater impact on HIV transmission than "formal" sex workers (Epstein, 2007; Morris and Kretzschmar, 1997; Hudson, 1996). This paper sheds light as to why these women do not choose to use condoms, and finds evidence that unexpected health shocks form part of the explanation.

To our knowledge, the relationship between shocks and the labor supply of sex workers has not been formally studied within economics. ${ }^{2}$ However, some qualitative sociological and anthropological research has suggested that women have sex with multiple partners or develop sexual networks for financial support and income security (Swidler and Watkins, 2007; Schoepf, 2004; Hunter, 2002; Wojcicki, 2002b). Researchers have also examined the types and amounts of gifts received from partners in informal or transactional sex relationships (Luke, 2006; Dunkle et al., 2004; Luke, 2003), but not the effect of income shocks or income risk on those transfers. In economics, our paper is somewhat related to Edlund and Korn (2002) in that we both study sex workers, but our paper adds health risk as an additional dimension and focuses on choices within transactional sex over time, rather than on the choice to enter the commercial sex market.

Perhaps the most relevant economics papers are Gertler, Shah, and Bertozzi (2005) and Rao, Gupta, Lokshin, and Jana (2003), both of which find significant compensating differentials for unprotected sex (compared to protected sex) among CSWs. However, our focus here is not on

\footnotetext{
${ }^{1}$ Chetty and Looney (2006) also discuss these issues.

${ }^{2}$ One somewhat related paper is Ahlburg and Jensen (1998), which suggests that rural families mitigate interpersonal income risk by sending a family member into urban commercial sex work. Their argument focuses primarily on migration and secondarily on interpersonal risk, whereas we deal with intertemporal risk.
} 
the premium itself but whether the existence of a premium allows women to increase the amount of unprotected sex that they supply as a strategy to deal with health shocks. In this respect, this paper also contributes to recent work examining whether sexual behavior might be rational given certain economic conditions (Oster, 2007). ${ }^{3}$

\section{Theoretical Framework}

In this section, we present a simple model of sex work in an intertemporal labor supply framework. The model is in the spirit of MaCurdy (1981) and Kochar (1995, 1999). The sex worker is assumed to live for $T$ periods and to maximize lifetime expected utility over consumption $c_{t}$ and health risk $h_{t}$ as follows:

$$
\max E\left[\sum_{s=t}^{T-t} \delta^{s-t} u\left(c_{s}, h_{0}, \ldots, h_{s-1}, h_{s}\right) \mid \Omega_{t}\right]
$$

where $\delta$ is the discount rate, and $\Omega_{t}$ is information available at time $t$. We assume that

$\frac{\partial u\left(c_{s}, h_{0}, \ldots, h_{t-1}, h_{t}\right)}{\partial h_{t}}<0$, to reflect disutility from work, as well as the cost of pregnancy or the disutility from certain risky sex acts such as anal sex, experiencing the symptoms of an STI, or the health and socioeconomic consequences of HIV infection. Utility also depends on the history of past health risks taken. In particular, we assume that $\frac{\partial u\left(c_{s}, h_{0}, \ldots, h_{t-1}, h_{t}\right)}{\partial h_{k}} \leq 0$ for all $k<t$ : quality of life is lower for women that are at greater risk of being HIV positive. ${ }^{4}$

The woman's intertemporal budget constraint is

$$
A_{t+1}=\left(1+r_{t}\right)\left(P\left(h_{t}\right)+A_{t-1}-c_{t}\right)
$$

where $A_{t}$ represent assets, $r_{t}$ is the interest rate, and $P\left(h_{t}\right)$ is the total price paid by all clients on date $t$. The price is assumed to be increasing in $h_{t}$ (as it is empirically); otherwise, women

\footnotetext{
${ }^{3}$ The paper is also related to Dupas (2007), who evaluates an intervention to reduce risky sex along the intensive (whom to have sex with) rather than extensive (whether to have sex or not) margin. Similarly, our paper is focused on risky choices within transactional sex, rather than on the decision whether to engage in transactional sex or not.

${ }^{4}$ We do not impose any functional form on the utility function, but one example that fits into this framework would be one in which a woman's utility is unaffected until she develops AIDS, is declining thereafter, and is 0 after she dies.
} 
would never have unprotected sex. We follow the literature and assume that this comes from the fact that clients derive utility from unprotected sex and are willing to pay more to forego condom usage. ${ }^{5}$

Assuming an interior solution, the first order conditions at time $t$ are that

$$
\begin{gathered}
\sum_{s=t}^{T-t} \delta^{s-t} \frac{\partial u\left(c_{s}, h_{0}, \ldots, h_{s}\right)}{\partial h_{t}}+\lambda_{t} P^{\prime}\left(h_{t}\right)=0 \\
\frac{\partial u\left(c_{t}, h_{0}, \ldots, h_{t}\right)}{\partial c_{t}}-\lambda_{t}=0 \\
\lambda_{t}=\delta(1+r) E\left[\lambda_{t+1} \mid \Omega_{t}\right]
\end{gathered}
$$

where $\lambda_{t}$ represents the marginal value of wealth at time $t$.

The last equation makes explicit that the marginal value of wealth at time $t$ depends on expectations of future wealth. If a woman receives a permanent negative shock to her income such that $E\left[\lambda_{t+1} \mid \Omega_{t}\right]$ increases, then $\lambda_{t}$ increases and $c_{t}$ decreases. In addition, the amount of health risk that the woman chooses to take increases, from (3). Equation (3) also implies that women that believe themselves to already be at significant risk of being HIV positive will increase their supply of risky sex by more than women that believe their risk is smaller (since the marginal cost of accepting greater risk is smaller for these women).

In this paper, however, we are interested in the effect of transitory shocks that are small relative to lifetime income. Since these shocks are small, they should have no effect on $E\left[\lambda_{t+1} \mid \Omega_{t}\right]$ or $\lambda_{t}$, and so should have no effect on the amount of health risk that is accepted. Instead, these shocks should be smoothed through the use of savings (i.e., Paxson, 1992). However, if savings and credit are unavailable so that the 1-period budget constraint binds, then it is possible that a woman may adjust her accepted health risk in response to even small, short-term income shocks. ${ }^{6}$

\footnotetext{
${ }^{5}$ See Gertler, Shah, and Bertozzi (2006) for a model of sex work that derives this condition explicitly.

${ }^{6}$ Few women in our sample have formal savings accounts (see Table 1) or access to bank credit, but most save money informally at their home and have access to gifts and loans from friends and family.
} 
The implication of this simple model - that labor supply may adjust to short-term income shocks in the absence of perfect consumption smoothing - is not new, but the importance of our study is that the increase in labor supply comes at great individual cost in terms of increased risk of contracting HIV or other STIs. The increased health risk will also likely impose an external cost on society as a whole, as HIV is transmitted between sex workers and clients and then on to other partners. In addition, quite apart from any efficiency calculation, the tests in this paper are of significant importance in terms of designing interventions to limit the spread of HIV by sex workers.

\section{Research Design}

\subsection{Background on Busia, Kenya}

Our study takes place in Busia District, a rural area in Western Province, Kenya with a semiurban center, Busia Town. The estimated HIV prevalence in Busia District is $9.8 \%$, compared to the national average of $6.7 \%$ (Central Bureau of Statistics, 2004). Busia Town has a population of 44,196 (Central Bureau of Statistics, 2001) and is located on the Ugandan border, along one of two major trucking routes from the port city of Mombasa (on the Indian Ocean) to Kampala, via Nairobi.

Truck stops are often where sex workers congregate, and Busia was identified as a "hot spot" for commercial sex activity due to the high volume of trucks overnighting. A GIS-based study conducted by the Strengthening STD/HIV Control Project in Kenya (SHCP) found that Busia received approximately one-quarter of the trucks overnighting at the Kenya-Uganda border (National Aids Control Council, 2005). ${ }^{7}$ Unlike sex workers in many developed countries and in urban areas of developing countries, however, many of the sex workers in Busia do not selfidentify as commercial sex workers (CSWs). Many of the women are orphans, all are widowed, divorced, or separated, and most identify themselves as "survivors": women who engage in sex work in order to survive. The women in our sample range from formal commercial sex workers

\footnotetext{
${ }^{7}$ The other major border town is Malaba, which receives about three times as many overnight trucks as does Busia.
} 
to women who engage in informal transactional sex.

\subsection{Identifying Commercial Sex Workers}

To obtain a representative sample of women engaged in sex work in Busia Town, we identified women through a peer group network which was originally established by the Strengthening STD/HIV Control Project in Kenya (SHCP), a Kenyan organization associated with the University of Manitoba and the University of Nairobi that worked with thousands of formal and informal sex workers across Kenya. SHCP began working in Western Kenya in 1999 by organizing women into peer groups of 15 to 30 women each. Each group is led by a peer educator, and the peer groups within each district are supervised by a trained nurse who serves as a field coordinator. Though SHCP was phased over to the government in October 2005, the peer groups within a district continue to operate essentially as community-based organizations.

Working with the University of Nairobi Institute for Tropical and Infectious Diseases (UNITID), this study began in October 2005. By that time, SHCP had recruited approximately 400 women into 30 peer groups in Busia Town. The field coordinator for the district was employed as an enumerator for this project and was assisted by one of the peer educators. To identify a sample of formal and informal sex workers, we used the same definition as SHCP: any single, widowed, divorced, or separated woman, aged 18 or older, who had multiple concurrent sex partners. We asked each peer group member to provide a list of all the women living in Busia Town she knew who fit this description. For the purposes of this paper, we do not focus on the distinction between formal and informal sex workers.

We identified 1,205 sex workers in Busia Town from this "snowball" technique. ${ }^{8}$ Assuming

\footnotetext{
${ }^{8}$ Working with a sample identified by women in SHCP-organized peer groups has advantages and disadvantages. One advantage is that women in the peer groups know other single women in their community with multiple concurrent sexual partners, which should increase the size and improve the representativeness of the identified sample. Furthermore, the structure of the peer groups allows peer educators and peers to better locate the sex workers whom they identify. Finally, SHCP has had a long, stable relationship with sex workers in Western Province, so that sex workers trust the organization, which tended to limit non-participation and attrition among sampled sex workers. The major disadvantage is that the women identified in this way may not be fully representative of the sample of sex workers in Busia Town. As in any snowball sampling technique, the sample includes fewer women right at the margin of participation in transactional sex.
} 
that the age distribution of females in Busia is similar to that reported in the 2003 Kenyan Demographic and Health Survey for the rest of rural Kenya, we estimate that $11.6 \%$ of Busia women aged 15-49 earn some income from sex work. From this, we argue that the women involved in this project are not particularly atypical of the average woman in Busia Town, and that the results of this study are generalizable to a significant proportion of the female population in Kenya.

\subsection{Data Collection}

Of the 1,205 women that were identified, a random sample of 248 women were selected for project participation, stratified by peer group. The data collection took place in two rounds: Round 1 occurred between October and December, 2005, and Round 2 occurred between July and October, 2006. We asked each woman to keep a daily diary for the duration of each round in which she self-reported her income, expenditures, the transfers she had given and received, and the shocks she had encountered that day. We focus on three types of shocks in this study: own illness or injury, illness or injury of another household member, and the incidence of a sexually transmitted infection. Illness is an indicator variable that is coded as 1 if the individual reported having a cough, fever, diarrhea, cuts, or burns, or had reported suffering from malaria, typhoid or any other illness.

In the diaries, women were also asked to record detailed information on each encounter with a client, including the activities performed, whether a condom was used, and the price that was paid (both in cash and in goods or services). After a preliminary analysis of the Round 1 data, some additional questions were added to the Round 2 diaries. The additions which are relevant to this paper included questions on client characteristics and somewhat more detailed questions on the transfers received from regular clients. In each round, each respondent kept the diary for a period of 3 months, though the first few weeks were often not usable in the final analysis due to reporting errors made as women were learning the diaries.

The diaries were extensively pre-tested by the authors, a research assistant, and the two enumerators to maintain respondent confidentiality, meet norms of cultural sensitivity, and to ensure that respondents understood all of the questions. To ensure data quality, the two 
enumerators conducted diary checks roughly once a week, during which they checked for errors and resolved mistakes with respondents.

In order for women to keep these self-reports, it was of course necessary that they could read and write Kiswahili, one of the official languages in Kenya and the language used in the diaries. Literacy levels in the sample were relatively high: $95 \%$ of the sample could read Kiswahili, and $88 \%$ could write Kiswahili (Table 1). To avoid losing illiterate women, a special effort was made to keep them in the sample. Each illiterate woman was assigned a peer educator who met with her daily to read the diary questions and fill in the answers for her.

In addition to the diaries, a background questionnaire in the style of the World Bank Living Standards Measurement Surveys was also administered by the enumerators. This survey included questions on family background, household characteristics, education, migration, land and durable good ownership, access to credit and savings, knowledge of HIV/AIDS, attitudes towards sex work, and other related questions. To compensate respondents for keeping the diaries, we paid women in Round 1 1,000 Kenyan shillings (US \$14), and women in Round 2 1,500 Kenyan shillings (US \$21) for their participation. ${ }^{9}$ Of the 248 women that were sampled, we obtained complete, usable data from 192 of them (77\%). The other women could not be included because they refused to participate or stopped filling out the diaries during the sample period, because they moved to another area and could not be traced, or because they kept the diaries poorly or did not fill them completely. In total, the final dataset consists of 192 women, 18,894 transactions, and 12,199 sex worker days. ${ }^{10}$

\subsection{Descriptive Statistics}

\subsubsection{Background Statistics}

Background statistics for our sample of sex workers are presented in Table 1. Panel A shows that the average sex worker is 28 years old, has completed over 9 education grades, and has

\footnotetext{
${ }^{9}$ Round 2 participants were compensated slightly more because the diaries were more detailed and took more time to complete.

${ }^{10}$ The breakdown of the final sample by round is 84 women in Round 1 and 91 in Round 2, with 17 women in both rounds, so that pooled regressions are in most cases reported for 192 women. The actual number of observations in each regression differs depending on available data.
} 
roughly 2 children and 3 dependents. ${ }^{11}$ Eighty-four percent of these women are heads of their households. Twenty-three percent of the sex workers in the sample are widowed, $20 \%$ are divorced or separated, $13 \%$ are currently cohabitating, and $44 \%$ were never married and are not currently cohabitating. In total, about $43 \%$ of the women are previously widowed, divorced, or separated, which is much higher than the proportion of $10.2 \%$ found among the general population of Kenyan women aged 15-49 (Central Bureau of Statistics, 2004). The high number of previously married women is consistent with sociological and anthropological studies of sex workers in rural areas, and it is likely that many are HIV widows (Swidler and Watkins, 2007; Wojcicki, 2002a).

Panel A also presents statistics on the effect that sex work has had on sex workers' perceptions of the likelihood that they will eventually marry (or remarry). Only $3 \%$ of women report that working in the commercial sex industry has made the prospect of future marriage less likely, but $41 \%$ report that working in sex work has made marriage more likely. This is notable because one explanation for the significant wage premium to sex work is that it serves as a compensating differential for reduced marriage market possibilities (Edlund and Korn, 2002). These results, however, seem to suggest that this explanation is unlikely to be important for this population of sex workers and is consistent with Arunachalam and Shah (2008). ${ }^{12}$

HIV knowledge characteristics are shown in Panel B of Table 1. Sixty percent of the sample has been tested for HIV, which is much higher than the national average $(14.7 \%)$ or the average for Western Province (14.6\%) among women aged 15-49 (Central Bureau of Statistics, 2004). The women scored very highly (with an average score of 94 out of 100) on a test of HIV knowledge that covered HIV transmission pathways, the relationship between HIV and AIDS, risk reduction methods, and misconceptions surrounding HIV/AIDS. Taken together, Panel B suggests that most sex workers in Busia are quite aware of the health risks related to HIV/AIDS.

Finally, Panel C presents summary statistics on access to formal credit and savings. Though

\footnotetext{
${ }^{11}$ The education level of women in our sample is similar to that of the average Kenyan woman. Fifty-seven percent of our sample have completed primary school, compared to $56 \%$ across Kenya and $67 \%$ across Western Province (Central Bureau of Statistics, 2004).

${ }^{12}$ It is also possible that supplying commercial sex affects marriage prospects on the intensive (partner quality) rather than extensive (finding a partner) margin.
} 
$37 \%$ of sex workers report having a savings account, almost all of these savings accounts are group arrangements (mostly arranged through SHCP) that do not easily allow for withdrawals. Indeed, among women with accounts, average savings withdrawals in the month prior to the survey were just 73 Kenyan shillings (Ksh), equivalent to about US $\$ 1.04$. Instead of relying on formal mechanisms, women tend to save through Rotating Savings and Credit Associations (ROSCAs): sixty-four percent of women participate in ROSCAs, and the average sex worker that participated in a ROSCA saved over 7,000 Kenyan shillings (US \$100) in her ROSCA in the past year (not shown). However, nearly all of these ROSCAs have a predetermined payout schedule and so are not ideal for consumption smoothing purposes, as discussed in Gugerty (2007).

\subsubsection{Shocks, Transfers, and Expenditures}

In this study, we focus on three types of health shocks that are commonly experienced by sex workers. The first is an indicator that is coded as 1 if the sex worker reported having a fever, cough, diarrhea, typhoid, malaria, cuts, burns, or other injuries or illnesses. The second is whether the sex worker reported that another member of the household suffered from any of these illnesses. The third is the occurrence of sexually transmitted infections (STIs), which should presumably affect a woman's ability to supply sex. ${ }^{13}$

Panel A of Table 2 presents summary statistics for these 3 shocks. Column 1 presents the daily averages. Women reported household sickness on $37 \%$ of days, own sickness on $34 \%$ of days, and STIs on $3 \%$ of days. Column 2 reports the percentage of women that reported these shocks at least once over the 3 month data collection period. Each percentage is high, ranging from $34 \%$ for STIs to $98 \%$ for own sickness.

Panel B presents statistics on access to informal finance, including transfers given to and received from friends and family members, and gifts received from regular clients. On an average day, women send about $32 \mathrm{Ksh}$ (US \$0.46) in gifts and loans to friends and family, and receive about 55 Ksh (US \$0.79) back. Women receive another 90 Ksh (US \$1.29) per day in gifts from

\footnotetext{
${ }^{13}$ We also collected information on other shocks, including the death of a friend or family member, but do not include them in the analysis as they have ambiguous effects on labor supply. For instance, women may need to work more to afford funeral contributions but may work less to attend the funeral itself.
} 
regular clients. Though we do not have a detailed breakdown on the types of gifts given in Round 1, the Round 2 data indicates that most of these gifts came in the form of cash or in-kind payments, though regulars also occasionally pay for rent or other expenses. Overall, women appear to be relatively well connected to these informal credit markets, though the amounts that are typically transferred on an average day are small.

Panel C presents statistics on daily expenditures. Average total expenditures are about 655 Ksh (US \$9.36) per day and average food expenditures are 148 Ksh (US \$2.11) per day. Though national estimates of average per capita expenditures are hard to come by in Kenya, these figures are certain to be significantly higher than the Kenyan average.

\subsubsection{Labor Supply and Sexual Behavior}

Table 3 presents summary data on labor supply and sexual behavior for the sex workers in the sample. Panel A shows that the average women makes about 680 Kenyan shillings (US $\$ 9.71$ ) per day in sex work, compared to about 100 shillings (US \$1.43) from other sources (such as agriculture, small business, or salaried work at bars or restaurants). The average woman engages in sex work on a bit more than 3 out of every 4 days and sees an average of 1.52 clients per day. ${ }^{14}$ As in other studies of sex work, average income in the sample is very high relative to the average in the area: income from sex work is approximately 7 times that of other daily income earners in Busia District (Robinson, 2007). This difference is significantly higher than the $56 \%$ income premium in Mexico found by Gertler, Shah, and Bertozzi (2005) and the 37\% wage premium found by Rao et al. (2003) in Calcutta, and more in line with the much larger premium found by Booranapim and Mainwaring (2002) in Thailand.

The next few rows in Table 3 report mean sexual behavior in the sample. For each variable, Column 1 presents the overall daily average, and Columns 2-4 includes transaction level data. Column 1 indicates that, over all the days covered (including those in which they did not work), women have vaginal sex on $74 \%$ of days, anal sex on $22 \%$ of days, and oral sex on $19 \%$ of days. Women have unprotected sex on $18 \%$ of days, and have an average of 0.42 unprotected sex acts

\footnotetext{
${ }^{14}$ While we do have data on hours worked, we do not report the hours here as it is difficult to determine if they truly represent work. For example, a woman may spend all night with one client, but part of the time may be spent sleeping.
} 
per day. From Column 2, women have vaginal sex with $95 \%$ of clients, anal sex with $23 \%$ of clients, oral sex with $19 \%$ of clients, and unprotected anal or vaginal sex with $16 \%$ of clients.

One important distinction between clients is those that are considered regulars and those that are considered casuals. Though this distinction is not completely clear, regular clients have had repeated encounters with a given woman and may be considered a boyfriend, lover, or partner. In focus group discussions, the women often cited emotional support and love as characteristics associated with a regular client. In contrast, casual clients are often not known to the sex worker before the transaction. Since casual clients can become regular clients over time, and many women have multiple regular clients, the definition of a regular and casual client can be hard to define. However, since SHCP had already been using the regular and casual client terminology, we allowed the respondents to determine on their own if a particular client should be classified as a regular or casual. Columns 3 and 4 provide transaction level data on services provided to regular and casual clients. The major differences between regular and casual clients are in anal sex and in unprotected sex. Sex workers are slightly more likely to have anal sex with casuals ( $21 \%$ of the time, compared to $17 \%$ of the time with regulars), but are more likely to have unprotected sex with regulars ( $21 \%$ of the time, compared to $14 \%$ with casuals). This may be because women are more aware of the risk profile of regular clients than they are of casual clients.

Finally, Panel C presents the percentage of women that engaged in various sexual activities at least once during the sample period. Interestingly, $82 \%$ of women engaged in anal sex and $70 \%$ engaged in unprotected vaginal or anal sex. The anal sex figures are particularly interesting, because they are much higher than those presented in other sources. ${ }^{15}$ For instance, Brody and Potterat (2003) review a wide variety of public health and anthropological studies and find a maximum anal sex prevalence figure of $42.8 \%$ in self-reported recall data. The authors argue, however, that most anal sex figures are likely underestimates, as respondents are much more likely to admit to having anal sex in a diary or in a computer questionnaire, neither of which are commonly used in Africa. Among a very similar group of sex workers in Kenya, Ferguson and Morris (2003) find that only 20\% of CSWs in the Kenyan Highlands responded that they

\footnotetext{
${ }^{15}$ We thank Damien de Walque for pointing this out to us.
} 
had ever had anal sex. ${ }^{16}$

As mentioned previously, roughly $44 \%$ of the women in this sample participated in peer groups sponsored by the Strengthening STD / HIV Control Project in Kenya and received education about HIV and other STIs, as well as increased access to condoms. This is one reason why women may have scored so highly on the test of HIV knowledge presented in Table 2. Compared to the marginal sex worker, these women should be more aware of the risks of unprotected sex, so the figures in Table 3 are likely to be lower bounds on the frequency of unprotected sex among sex workers in rural Africa.

\section{Risk Premium}

\subsection{Estimation}

We will estimate a risk premium by performing a fixed effects regression of the price paid by the client on the activities performed, and whether a condom was used. Ideally, this regression should control for client characteristics. However, we only have panel information on clients for a small portion of our data, so we will have to assume homogeneity on the demand side for most of what follows. This leaves us with an estimating equation of the type

$$
P_{i t}=\sum_{h=1}^{H} \beta_{h} X_{h i t}+\sum_{a=1}^{A} \beta_{a} X_{a i t}+\alpha_{i}+v_{t}+\varepsilon_{i t}
$$

for sex worker $i$ at date $t$. This is an equation relating the price $P_{i t}$ to the performance of risky sexual activities $X_{h i t}$ and other activities $X_{\text {ait }}$. Assuming homogeneity in demand on a particular date, the individual fixed effect $\alpha_{i}$ will pick up differences across women in bargaining power and in the willingness to accept risk, while other time-varying effects such as changes in demand on particular days will be captured with date controls $v_{t}\left(v_{t}\right.$ includes controls for the day of the week and the month of the year). $\varepsilon_{i t}$ is a random disturbance term that may capture unmeasured factors such as a woman's or client's mood at a particular time. If this regression is properly specified, $\beta_{h}$ will reflect the risk premium to the risky activity $X_{h i t}$ (mainly unprotected

\footnotetext{
${ }^{16}$ To explore the implications of anal sex for HIV transmission, we should ideally have measures of unprotected anal sex. We only have this information for part of our sample, however.
} 
sex). ${ }^{17} X_{\text {ait }}$ will consist of all other activities that do not fundamentally involve an increase in risk of contracting HIV, such as providing company or performing a massage.

\subsection{Results}

The results from estimating Equation (6) are presented in Table 4. Regressions in Columns 1-3 are conducted on the entire sample, while regressions in Columns 4-6 are restricted to the Round 2 sample in order to include client characteristics as explanatory variables. In addition to the variables shown, all regressions also include a control for the round of data collection. The variable used to estimate the compensating differential for unprotected sex is an indicator variable equal to 1 if the woman had at least 1 unprotected sex act (with anal and vaginal sex aggregated together). ${ }^{18}$

The results suggest a sizeable risk premium to unprotected sex and to the provision of other services. The premium to anal sex is approximately 74 Kenyan shillings (US $\$ 1.06$ ), which can be explained partially through the increased health risk. ${ }^{19}$ Also of note is the 69 shilling (US $\$ 0.99$ ) return to company, which likely reflects unobserved characteristics of clients that request company. Column 1 also shows that unprotected anal or vaginal sex is associated with a 38 shilling (US \$0.54) increase in the price. As the total average price paid is 485 shillings, this amounts to a premium of about $7.8 \%$, which is rather low when compared with the risk premium of $23 \%$ calculated by Gertler, Shah, and Bertozzi (2005). However, the market for sex work in Mexico, where sex work is legal and regulated and where average incomes are higher, is likely to differ greatly from the Kenya context. The lower risk premium may also be the result of

\footnotetext{
${ }^{17}$ Protected anal sex may be considered risky as well because of the increased likelihood of tearing a condom during anal intercourse.

${ }^{18}$ We obtained similar estimates using the number of unprotected sex acts as a regressor, and by disaggregating unprotected sex into unprotected anal and unprotected vaginal sex. These latter estimates are much less precise because those measures were only available in the round 2 data.

${ }^{19}$ Studies on HIV transmission through male-to-female anal sex are very rare, and causality is difficult to establish, but sex workers in South Africa that supply anal sex (either protected or unprotected) have been found to have a 10-120\% increase in the risk of HIV infection (Karim and Ramjee, 1998). Similarly large increases have been estimated for couples in Europe (European Study Group on Heterosexual Transmission of HIV, 1992). We are not aware of studies that estimate the per-act transmission probability for heterosexual anal sex in Africa.
} 
differences in data - Gertler, Shah, and Bertozzi (2005) collect recall data on the last three to four client transactions rather than a longer panel. In addition, only $11.7 \%$ of their sample has variation in condom usage with clients, while $70 \%$ of our sample has variation in condom usage.

Columns 2 and 3 run the same specification among the regular and casual client samples separately. The differences between regular and casual clients in the prices paid for various activities are not significantly different (tests not shown), but regular clients actually pay more for unprotected sex than do casual clients (the difference is not significant). These results suggest that women are compensated for risk even by regular clients, and that women have at least some discretion over the activities they perform.

Columns 4-6 restrict attention to the Round 2 data, so that we may estimate the effect of client characteristics (as reported by the sex worker) on prices. These characteristics include whether the client is circumcised, the client's wealth level, attractiveness, and occupation, and whether the sex worker thinks the client is at high risk of having HIV/AIDS. We also include controls for tribe and cleanliness, though we do not include these coefficients in the Table. Unfortunately, many of the client characteristics are missing because women often failed to keep track of this information. As these non-responses are almost certainly non-random, we need to be cautious in interpreting the results (though the inclusion of fixed effects should eliminate some bias across women).

That said, the results in Columns 5 and 6 make intuitive sense. Prices are higher (though the coefficient is insignificant) for wealthier clients and lower (significant at 5\% or 10\%, depending on the specification) for more attractive clients. The price does not seem to be significantly higher for clients whom the sex worker raters to be at high risk of having HIV/AIDS.

In sum, the results of Table 4 are consistent with the notion that sex workers have some discretion in choosing whether to use a condom, that a risk premium exists to unprotected sex, and that it may be rational for women to choose to engage in unprotected sex to capture the risk premium. In the next section, we test whether women choose to do this. 


\section{Consumption Smoothing and the Supply of Unprotected Sex}

\subsection{Estimation}

The simple model in Section 2 predicts that consumption and risky sexual behavior will respond to permanent income shocks but not to transitory shocks that do not affect the lifetime budget constraint. To examine these relationships empirically, we will estimate fixed effects equations of the type

$$
\begin{aligned}
& h_{i t}=\beta S_{i t}+\alpha_{i}+v_{t}+\varepsilon_{i t} \\
& e_{i t}=\gamma S_{i t}+\widetilde{\alpha}_{i}+\widetilde{v}_{t}+\widetilde{\varepsilon}_{i t}
\end{aligned}
$$

where $h_{i t}$ is a measure of unprotected sex, $e_{i t}$ represents household expenditures (we did not collect consumption data), and the fixed effects $\alpha_{i}$ and $\widetilde{\alpha_{i}}$ are meant to proxy for individualspecific variables, notably preferences and the marginal utility of lifetime wealth. $v_{t}$ and $\widetilde{v}_{t}$ include controls for the day of the week and the month of the year. $S_{i t}$ is an indicator variable equal to 1 if the household encountered a health shock, and $\varepsilon_{i t}$ and $\widetilde{\varepsilon_{i t}}$ are iid error terms.

An equation like (8) is often used to test for consumption smoothing. If the estimated $\gamma$ cannot be differentiated from 0 , consumption smoothing is often considered efficient and individuals are thought of as being relatively well insured from intertemporal income risk. However, such an estimation does not provide any information on how individuals choose to cope with risk. For instance, $\gamma$ may be close to 0 if individuals engage in costly income smoothing (Morduch, 1995), if individuals are risk averse and choose to maintain consumption in the face of income shocks by incurring costs such as reducing human capital or health investments in household members (Jacoby and Skoufias, 1997; Chetty and Looney, 2006), or if households use productive assets such as bullocks to smooth consumption (Rosenzweig and Wolpin, 1993). As we will discuss below, our own estimated $\gamma$ is very low, but women incur significant (expected) health costs by increasing their supply of risky sex in response to income shocks. 


\subsection{Results}

\subsubsection{Expenditures}

Before examining the labor supply responses to health shocks, we perform fixed effects regressions of daily levels of various expenditure categories on the 3 types of shocks previously discussed: whether a woman is sick herself, whether a member of her household is sick, and whether a woman is suffering from an STI. We also include an indicator for the first day after having experienced an STI. Since experiencing an STI often precludes supplying sex, women can only adjust their behavior after the STI has passed. All dependent variables are aggregated at the day level, so there is only one observation per woman. Results are presented in Table 5 .

For all of the shocks, total and private expenditures ${ }^{20}$ seem to be insensitive to the occurrence of income shocks. For instance, private expenditures actually increase by about 11 shillings (US \$0.16) when another household member gets ill, and food expenditures are insensitive to all of these shocks. Taken at face value, these results suggest that sex workers are well insured against unexpected income shocks, though this result says nothing about how consumption smoothing is achieved. As the next few Tables will show, sex workers maintain consumption in large part by increasing their supply of unprotected sex and accepting significant health costs.

\subsubsection{Participation in the Sex Sector and the Supply of Unprotected Sex}

Table 6 presents fixed effects estimates of the impact of the various shock measures on labor supply. Starting with Panel A, own sickness has the expected effect for all labor supply measures: women are less likely to participate in the commercial sex market when they are sick. The more interesting result is the effect of household sickness on labor supply. Women are 2.7 percentage points more likely to see a client when a household member falls ill. This amounts to a $3.2 \%$ increase in the probability of participating in the sex sector. As can be seen in Columns 3 and 4, women increase their participation by taking on more casual clients. This is notable because women usually do not know casual clients before the transaction, so they probably can be less sure of the probability that a casual client is HIV positive than they could be of a regular client.

\footnotetext{
${ }^{20}$ Private expenditures include alcohol, soda, cigarettes, meals in restaurants, clothing, health and beauty products, and other privately consumed categories such as airtime for cellular phones.
} 
Columns 5-7 show that women adjust their labor supply in the commercial sex sector rather than in other sectors in which they work.

Panel B presents results for experiencing the symptoms of a sexually transmitted infection (STI). As expected, experiencing an STI reduces the probability of supplying transactional sex, and represents a sizeable income shock: total income decreases by $177 \mathrm{Ksh}$ on such days (US $\$ 2.53$. If women are unable to use risk coping mechanisms to cope with such a big income shock, they may choose to work more after recovering from the STI, and Panel B suggests that they do just this. Though not all of the responses are statistically significant at traditional levels due to the rarity of STI shocks (occurring on 3\% of days), all of the coefficients in the regressions related to sex work are positive. Women see 0.265 more clients and earn an additional 233 Ksh (US \$3.33) from sex work on days after recovering from an STI.

These responses are very similar to $\operatorname{Kochar}(1995,1999)$, who shows that individuals work more when their households incur negative income shocks. In this paper, we are ultimately interested in how the supply of unprotected sex responds to health shocks, since an increase in unprotected sex entails a significant (expected) health cost on women, especially for women that are HIV negative. If unprotected sex is indeed very sensitive to short-term health shocks, then alternative consumption smoothing mechanisms must be quite inefficient, and the provision of more effective smoothing mechanisms could have substantial benefits in reducing the spread of HIV.

Table 7 presents fixed effects regressions of unprotected sex measures on health shocks. The dependent variables are indicators for whether a woman had unprotected sex, the number of unprotected sex acts in which she engaged, and indicators for having anal, vaginal, or oral sex. All dependent variables are measured at the daily level. Panel A shows that women dramatically increase their supply of protected and unprotected sex in response to these short-term income shocks. When a household member falls sick, women are 3.2 percentage points more likely to have unprotected sex, 4.3 percentage points more likely to have anal sex, 2.3 percentage points more likely to have vaginal sex, and 3.7 percentage points more likely to have oral sex. In percentage terms, these are increases of $20.6 \%, 21.7 \%, 2.8 \%$, and $21.3 \%$, respectively. Women also have 0.068 more sex acts on such days, though the coefficient in this regression is not quite 
significant at $10 \%$. As will be discussed in more detail in Section 6, these increases substantially increase the likelihood of being infected with HIV.

Panel B, which focuses on STIs, shows a similar pattern with even larger coefficients, though the coefficients do not reach statistical significance due to the rarity of STIs. In a larger sample, we expect it would be possible to find statistically significant effects.

Taken together, Tables 6 and 7 suggest that the supply of sex (including unprotected sex) is very sensitive to even small, short-term income shocks. Furthermore, the results imply that intertemporal income risk might have a substantial impact on the likelihood that women who supply transactional sex become infected with HIV.

\subsection{Robustness Checks}

The results of the previous section suggest that sex workers accept a significant amount of health risk to deal with short-term illness shocks, which implies that other consumption smoothing techniques have failed. In this section, we provide several robustness checks to test more closely whether our results appear consistent with a consumption smoothing explanation for the labor supply response. Ideally we would be able to check whether responses are smaller for women that have access to formal consumption smoothing mechanisms such as individual savings accounts in a bank, but the vast majority of women in this sample are unbanked and only have access to group savings accounts that heavily restrict their withdrawals (see Table 1). For this reason, we are unable to compare women with varying levels of access to smoothing mechanisms. Instead, we examine how the results vary by income level and by perceived HIV status.

\subsubsection{Results by Income Level}

If women supply more risky sex as a consumption smoothing mechanism, it should be the poorest women that are most likely to use unprotected sex as a risk-coping technique, particularly since the average sex worker in Western Kenya makes significantly more than other daily income earners (i.e., Robinson, 2007). There remains significant heterogeneity in sex worker earnings, however: over the sample period, a woman at the 25th percentile of the sex worker income distribution earned $509 \mathrm{Ksh}$ (US \$7.27) per day, while a woman at the 75 th percentile earned 
1,089 Ksh (US \$15.56) per day.

To explore whether it is poorer women that are most sensitive to the shocks, we construct indicators for whether the sex worker's daily income is below the daily income of the median sex worker (US \$10.94), and interact this indicator with the household health shocks. Table 8 presents fixed effects regressions of sexual behavior on health shocks and the interactions. Since we are primarily interested in the sickness indicators, we present only those results in this Table.

The results are generally consistent with a consumption smoothing explanation as the interactions are generally positive, though several coefficients are not statistically significant. However, the interaction is significant for whether the sex worker participated in the transactional sex market, the number of clients (and casual clients) she saw, and whether she had vaginal sex. The coefficient for the regression for unprotected sex is not significant, though it is positive and large in magnitude.

In general, Table 8 suggests that poorer women are more sensitive to short term health shocks than are richer women. It is interesting to note, however, that certain responses appear to be statistically significant and substantial in magnitude even for richer women. For instance, we estimate that women in the top half of the sex worker income distribution increase the probability that they have anal sex by 3.1 percentage points on days in which a household member falls ill. This may suggest that responses are driven in part by behavioral biases such as reference-dependent preferences, at least for women at the top end of the sex worker income distribution.

\subsubsection{HIV Status and Labor Supply Responses}

We have shown that women increase their supply of unprotected sex when a household member falls ill, and have argued that accepting that health risk imposes a cost on women. However, sex workers are already at considerable risk of contracting HIV and so may already be HIV positive (or believe that they are likely to be HIV positive). If so, the additional health risk incurred may be relatively minimal (though the risk of STI infection is likely non-trivial). ${ }^{21}$

\footnotetext{
${ }^{21}$ In addition, unprotected sex can have negative health consequences for HIV positive women because it can lead to re-infection and to an increased viral load, which tends to speed up the development of AIDS.
} 
Though we cannot know if HIV positive women respond differently to shocks than do HIV negative women, since we did not test women for HIV, we did ask women if they had ever been voluntarily tested for HIV and what they thought their risk of being infected was. We classify as likely HIV positive any woman that had been tested for HIV and that responded that the probability that she was infected with HIV was over $50 \%$. We classify $7.0 \%$ of women as likely HIV positive in this way, a figure which is likely a major underestimate given that the HIV prevalence was $9.8 \%$ in this part of Kenya and sex workers are presumably more likely to be infected than the average Kenyan.

We first test whether the risk premium to unprotected sex differs between women that are classified as likely positive and other women. ${ }^{22}$ The results are presented in Appendix Table 1. The risk premium for women that are likely positive is just $18 \mathrm{Ksh}$ and statistically insignificant (due in large part to the small sample size), while the premium for other women is $44 \mathrm{Ksh}$ (which is statistically significant). The difference in the estimated premia is statistically significant, suggesting that women that believe they are positive charge a lower premium than do other women. ${ }^{23}$ This result lends additional support to the notion that the risk premium is rational.

The most important question for our analysis is whether it is only women that already believe that they are HIV positive that switch to unprotected sex when shocks occur. This question is crucial in understanding whether our results imply significant welfare loss for women due to inadequate consumption smoothing, and in understanding how the observed labor supply responses might affect the spread of HIV. Appendix Table 2 explores this issue by interacting the occurrence of health shocks with the indicator for whether the woman is likely to be HIV positive.

In general, it does appear that those women that are likely to be HIV positive are more likely to increase their supply of unprotected sex in response to health shocks, though women that are not likely to be positive also significantly increase the level of risk they accept. The

\footnotetext{
${ }^{22}$ We also examined whether women with higher scores on the HIV knowledge test we administered charged a different premium, but the interaction was insignificant.

${ }^{23}$ We also examined whether all women that reported having a greater than $50 \%$ chance of being HIV positive charged a lower premium than women that reported having a lower than $50 \%$ chance, but the difference in premia was not statistically significant.
} 
interacted term is positive in all regressions except for the regression on sex work income as a dependent variable ${ }^{24}$ though it is only statistically significant for the regressions on the indicator for participation in the transactional sex market and on having anal sex. However, women that are not classified as likely to be HIV positive still increase their probability of having unprotected sex and anal sex by 2.8 percentage points and 3.2 percentage points, respectively (compared to 3.2 and 4.3 percentage points, respectively, in the earlier specification, in Table 7$){ }^{25}$ In summary, responses seem to be higher for women that are likely to already be positive, though still high for women that are not. We conclude from this that HIV negative women incur significant health costs by increasing their probability of having unprotected sex in response to shocks.

\section{How Big is the Expected Health Cost?}

The increase in unprotected sex that we observe among sex workers in Western Kenya imposes at least some health cost on women. But how big are these costs in real terms? In this section, we estimate the increase in the probability of becoming infected with HIV due to inadequate consumption smoothing mechanisms. We conservatively do not include any costs associated with increases in the probability of becoming infected with an STI, and we do not take into account the increased risk of becoming infected with HIV while suffering from an STI (see Oster (2005) for more on this issue). We also do not include costs associated with reinfection. For these reasons, the estimates in this section should be thought of as lower bounds on the probability of HIV infection.

With that in mind, the probability of an HIV negative woman becoming infected after a sexual encounter with a client is $p_{\text {client }} * p_{\text {unprotected }} * t$, where $p_{\text {client }}$ is the probability that the client is HIV positive, $p_{\text {unprotected }}$ is the probability that the sex worker has unprotected sex with the client, and $t$ is the probability that an HIV positive client transmits the virus to the sex worker if they have unprotected sex. Clients of sex workers are at much greater risk of HIV

\footnotetext{
${ }^{24}$ This is due in part to the fact that women that are likely to be HIV positive charge a lower premium for unprotected sex.

${ }^{25}$ We also examined how labor supply responses differed for women reporting a greater than $50 \%$ chance of being infected (whether or not they had been tested), and found no difference between their behavior and that of women that reported a lower than $50 \%$ chance of infection.
} 
infection than other men: Côté et al (2004) and Lowndes et al. (2000) estimate that clients of sex workers have an HIV prevalence roughly 4-5 times that of the general population in Accra, Ghana, and Cotonou, Benin, respectively. We conservatively assume that the clients of sex workers have a $25 \%$ chance of infection (roughly 2.5 times that of the general population). We use 1/1000 as the transmission probability (Gray et al., 2001; Magruder, 2008).

From Table 7, the average sex worker has unprotected sex 0.342 times per day when her household does not experience a health shock, and 0.410 times per day when her household does. ${ }^{26}$ From Table 2, household health shocks occur on $37 \%$ of days. Thus, a woman that was perfectly insured from these health shocks would have unprotected sex roughly $365 * 0.342 \approx 125$ times per year, whereas the average woman in our sample would have sex $365 *(0.342 * 0.63+$ $0.41 * 0.37) \approx 134$ times per year. Assuming this woman is initially HIV negative, she is infected with probability $1 / 1000 * 0.25=0.00025$ after each unprotected sex act. We assume that the probability of infection from protected sex is 0 .

An initially HIV negative woman who is perfectly insured will be infected with probability $1-\left(1-t p_{\text {client }}\right)^{125 y}$ after $y$ years, while the average woman in our sample will be infected with probability $1-\left(1-t p_{\text {client }}\right)^{134 y}$. Table 9 summarizes the probability of infection after different time periods. As might be expected, the probability of infection is high even if women were perfectly able to smooth their consumption, since all of these women have a large number of unprotected sex acts. However, for women that use unprotected sex to cope with income risk, the probability of HIV infection is 0.2 percentage points higher after 1 year, 0.4 percentage points higher after 2 years, 1 point higher after 5 years, and 1.6 percentage points higher after 10 years. In percentage terms, these increases are on the order of 5-7\% after all time periods. Since the price premium to unprotected sex is just $44 \mathrm{Ksh}$ (US \$0.63), this means that women accept, for instance, a $7.1 \%$ increase in the risk of HIV infection after 1 year for about US $\$ 5.67$. Given average incomes of the women in the sample, the extra income earned does not seem adequate to compensate women for the risk that they are taking.

\footnotetext{
${ }^{26}$ Though the coefficient in this regression (in Table 7 ) is not quite significant at $10 \%$, we use the total number of sex acts rather than the probability of having unprotected sex since women typically have multiple partners in a day.
} 


\section{Discussion}

Using panel data from a sample of 192 formal and informal sex workers in Busia, Kenya, this paper is the first to quantitatively investigate the relationship between sex work and income risk. We conducted our study in rural Western Kenya, an area in which transactional sex is prevalent: we estimate that $11.6 \%$ of the adult female population aged 15-49 supplies at least some transactional sex. For this reason, our results are generalizable to a larger population of women than is true of studies of sex work in more developed countries, and our findings fit into the larger literature on risk-coping and consumption smoothing in poor countries.

Like many people in poor countries, the sex workers in our sample are subject to considerable income risk but lack effective formal or informal means of coping with that risk. To make up for income shortfalls, these women choose to increase their supply of better compensated but more dangerous and more unpleasant sex in order to capture the price premiums associated with these activities. In particular, we find that women are $3.2 \%$ more likely to see a client, $20.6 \%$ more likely to engage in unprotected sex, and $21.7 \%$ more likely to have anal sex on days in which a household member experiences a health shock. Women also appear to increase their supply of risky sex immediately after recovering from a sexually transmitted infection (STI), the symptoms of which likely make it difficult or impossible to engage in sex work until it is treated. Given the high HIV prevalence rate in this part of Kenya (9.8\%) and the large health risks associated with unprotected sex, these increases in risky sexual behavior have enormous health consequences.

These results, therefore, suggest that in addition to helping women exit sex work, there are opportunities to reduce the health risks within sex work beyond HIV education and condom distribution. Focusing specifically on household illness, sex workers may be better able to reduce their risky sexual behavior if their children and dependents had better access to health services or subsidized health inputs. Public health interventions aimed at children are likely to have positive externalities on the spread of HIV, and perhaps future evaluations of childhood disease interventions can monitor these effects.

The results of this paper suggest that the existing informal consumption smoothing mechanisms that are available to sex workers are inefficient and that women incur substantial health 
costs by choosing to increase their supply of risky sex as an alternative risk coping strategy. For this reason, the provision of formal consumption smoothing or risk coping mechanisms could substantially improve sex worker welfare, and could also potentially limit the spread of HIV.

Much remains unknown about the transactional sex market in developing countries, and this study has only been able to scratch the surface by focusing on intertemporal risk and the supply of unprotected sex. Future work might focus attention on the extensive decision to enter the commercial sex market in the first place, rather than on the intensive margin as we do in this paper. More research is crucial, however, in order to understand how best to design interventions to limit the spread of HIV, a disease which remains the leading cause of death in sub-Saharan Africa (UNAIDS, 2007).

\section{References}

[1] Ahlburg, Dennis A. and Eric R. Jensen (1998). "The Economics of the Commercial Sex Industry and its Implications for HIV/AIDS Prevention Policies." In Confronting AIDS: Evidence from the Developing World, M. Ainsworth, L. Fransen, and M. Over (eds.), Brussels: European Community.

[2] Arunachalam, Raj and Manisha Shah (2008). "Prostitutes and Brides?" mimeo, University of Melbourne and University of Michigan.

[3] Booranapim, Yardfon and Lynn Mainwaring (2002). "Risk and Reward in the Thai Sex Industry." International Journal of Social Economics 29 (10): 766-780.

[4] Brody, Stuart and John J. Potterat (2003). "Assessing the Role of Anal Intercourse in the Epidemiology of AIDS in Africa." International Journal of STD $\&$ AIDS 14 (7): 431-436.

[5] Caldwell, John C., Pat Caldwell, and Pat Quiggin (1989). "The Social Context of AIDS in Sub-Saharan Africa." Population and Development Review 15 (2): 185-205.

[6] Central Burea of Statistics (CBS) [Kenya] (2001). 1999 Housing and Population Census, Volumes 1 and 2. Nairobi, Kenya: CBS. 
[7] Central Bureau of Statistics (CBS) [Kenya], Ministry of Health (MOH) [Kenya], and ORC Macro (2004). Kenya Demographic and Health Survey 2003. Calverton, Maryland: CBS, $\mathrm{MOH}$, and ORC Macro.

[8] Chetty, Raj and Adam Looney (2006). "Consumption Smoothing and the Welfare Consequences of Social Insurance in Developing Countries." Journal of Public Economics 90 (12): 2351-2356.

[9] Côté, Anne-Marie et al. (2004). "Transactional Sex is the Driving Force in the Dynamics of HIV in Accra, Ghana." AIDS 18 (6): 917-925.

[10] Dunkle, K.L., R.K. Jewkes, H.C. Brown, G.E. Gray, J.A. McIntryre, and S.D. Harlow (2004). "Transactional Sex Among Women in Soweto, South Africa: Prevalence, Risk Factors and Association with HIV Infection." Social Science $\&$ Medicine 59 (8): 1581-1592.

[11] Dupas, Pascaline (2007). "Relative Risks and the Market for Sex: Teenage Pregnancy, HIV, and Partner Selection in Kenya." mimeo, Dartmouth College.

[12] Edlund, Lena, and Evelyn Korn (2002). "A Theory of Prostitution." Journal of Political Economy 110 (1): 181-214.

[13] Epstein, Helen (2007). The Invisible Cure: Africa, the West, and the Fight Against AIDS. New York: Farrar, Straus and Giroux.

[14] European Study Group on Heterosexual Transmission of HIV (1992). "Comparison of Female to Male and Male to Female Transmission of HIV in 563 Stable Couples." British Medical Journal 304 (6840): 809-813.

[15] Ferguson, Alan and Chester Morris (2003). "Assessing the Role of Anal Intercourse in the Epidemiology of AIDS in Africa." International Journal of STD \& AIDS 14 (12): 856

[16] Gertler, Paul and Jonathan Gruber (2002). "Insuring Consumption Against Illness." American Economic Review 92 (1): 51-70.

[17] Gertler, Paul, Manisha Shah, and Stefano M. Bertozzi (2005). "Risky Business: The Market for Unprotected Commercial Sex." Journal of Political Economy 113 (3): 518-550. 
[18] Gray, Ronald et al. (2001). "Probability of HIV-1 Transmission per Coital Act in Monogamous, Heterosexual, HIV-1-Discordant Couples in Rakai, Uganda." Lancet 357 (9263): 1149-1153.

[19] Gugerty, Mary Kay (2007). "You Can't Save Alone: Commitment and Rotating Savings and Credit Associations in Kenya." Economic Development and Cultural Change 55 (2): 251-282.

[20] Hawken, M.P., R.D. Melis, D.T. Ngombo, K. Mandaliya, L.W. Ng'ang'a, J. Price, G. Dallabetta, and M. Temmerman (2002). "Part Time Female Sex Workers in a Suburban Community in Kenya: A Vulnerable Hidden Population." Sexually Transmitted Infections 78 (4): $271-273$.

[21] Hudson, Christopher (1996). "AIDS in Rural Africa: A Paradigm for HIV-1 Prevention." International Journal of STD and AIDS 7 (4): 236-243.

[22] Hunter, Mark (2002). "The Materiality of Everyday Sex: Thinking Beyond Prostitution." African Studies 61 (1): 99-120.

[23] Jacoby, Hanan and Emmanuel Skoufias (1997). "Risk, Financial Markets, and Human Capital in a Developing Country." Review of Economic Studies 64 (3): 311-335.

[24] Karim, S.S. and Ramjee G (1998). "Anal Sex and HIV Transmission in Women." American Journal of Public Health 88 (8): 1265-1266.

[25] Kochar, Anjini (1995). "Explaining Household Vulnerability to Idiosyncratic Income Shocks." American Economic Review (Papers and Proceedings) 85 (2): 159-164.

[26] Kochar, Anjini (1999). "Smoothing Consumption by Smoothing Income: Hours-of-Work Responses to Idiosyncratic Agricultural Shocks in Rural India." Review of Economics and Statistics 81 (1): 50-61.

[27] Lowndes, Catherine et al. (2000). "Management of Sexually Transmitted Diseases and HIV Prevention in Men at High Risk: Targeting Clients and Nonpaying Sexual Partners of Female Sex Workers in Benin." AIDS 14 (16): 1523-2534. 
[28] Luke, Nancy (2003). "Age and Economic Asymmetries in the Sexual Relationships of Adolescent Girls in sub-Saharan Africa." Studies in Family Planning 34 (2): 67-86.

[29] Luke, Nancy (2006). "Exchange and Condom Use in Informal Sexual Relationships in Urban Kenya." Economic Development and Cultural Exchange 54 (2): 319-348.

[30] MaCurdy, Thomas (1981). "An Empirical Model of Labor Supply in a Life-Cycle Setting." Journal of Political Economy 89 (6): 1059-1085.

[31] Magruder, Jeremy (2008). "Marital Shopping and Epidemic AIDS." mimeo, Berkeley ARE.

[32] Morduch, Jonathan (1995). "Income Smoothing and Consumption Smoothing." Journal of Economic Perspectives 9 (3): 103-114.

[33] Morison, L., H.A. Weiss, A. Buve, M. Carael, S.-C. Abega, F. Kaona, L. Kanhonou, J. Chege and R.J. Hayes (2001). "Commercial Sex and the Spread of HIV in Four Cities in Sub-Saharan Africa." AIDS 15 (4): S61-S69.

[34] Morris, Martina, and Mirjam Kretzschmar (1997). "Concurrent Partnerships and the Spread of HIV." AIDS 11 (5): 641-648.

[35] National AIDS Control Council [Kenya] (2005). Kenya HIV/AIDS Data Booklet 2005. Nairobi, Kenya: National AIDS Control Council.

[36] Oster, Emily (2005). "Sexually Transmitted Infections, Sexual Behavior, and the HIV/AIDS Epidemic." Quarterly Journal of Economics 120 (2): 467-515.

[37] Oster, Emily (2007). "HIV and Sexual Behavior Change: Why not Africa?" NBER Working Paper \#13049.

[38] Paxson, Christina H (1992). "Using Weather Variability to Estimate the Response of Savings to Transitory Income in Thailand." American Economic Review 82 (1): 15-33.

[39] Plummer, F.A., N.J.D. Nagelkerke, S. Moses, J.O. Ndinya-Achola, J. Bwayo, and E. Ngugi (1991). "The Importance of Core Groups in the Epidemiology and Control of HIV-1 Infection." AIDS 5 (Supplement 1): S169-176. 
[40] Rao, Vijayendra, Indrani Gupta, Michael Lokshin, and Smarajit Jana (2003). "Sex Workers and the Cost of Safe Sex: The Compensating Differential for Condom Use Among Calcutta Prostitutes." Journal of Development Economics 71 (2): 585-603.

[41] Robinson, Jonathan (2007). "Limited Insurance Within the Household: Evidence from a Field Experiment in Western Kenya." mimeo, UC Santa Cruz.

[42] Rosenzweig, Mark and Kenneth Wolpin (1993). "Credit Market Constraints, Consumption Smoothing, and the Accumulation of Durable Production Assets in Low-Income Countries: Investments in Bullocks in India." Journal of Political Economy 101 (2): 223-244.

[43] Schoepf, Brooke Grundfest (2004). "AIDS in Africa: Structure, Agency, and Risk." In HIV and AIDS in Africa: Beyond Epidemiology, Ezekiel Kalipeni et al. (eds.), Malden MA: Blackwell Publishers: 121-132.

[44] Swidler, Ann and Susan Cotts Watkins (2007), "Ties of Dependence: AIDS and Transactional Sex in Rural Malawi." Studies in Family Planning 38 (3): 147-162.

[45] Townsend, Robert (1994). "Risk and Insurance in Village India." Econometrica 62 (3): 539-591.

[46] UNAIDS (2002), Sex Work and HIV/AIDS: UNAIDS Technical Update. Geneva: UNAIDS.

[47] UNAIDS (2004), Epidemiological Fact Sheet - 2004 Update (Kenya). Geneva: UNAIDS.

[48] UNAIDS (2007). AIDS epidemic update: December 200\%, Geneva: UNAIDS.

[49] Wojcicki, Janet Maia (2002a), "Commercial Sex Work or Ukuphanda? Sex-for-Money Exchange in Soweto and Hammanskraal Area, South Africa." Culture, Medicine, and Psychiatry 26 (3): 339-370.

[50] Wojcicki, Janet Maia (2002b), “'She Drank His Money:' Survival Sex and the Problem of Violence in Taverns in Gauteng Province, South Africa." Medical Anthropology Quarterly $16(3): 267-293$. 
Table 1. Background Characteristics

Panel A. Background Information

Age

28.43

(6.98)

Educational Attainment

9.20

(2.69)

Literacy

Read Kiswahili

0.95

Write Kiswahili

0.84

Number of Biological Children

2.06

(1.83)

Total \# of Dependents

2.96

(2.36)

Age Began Seeing Clients

18.67

(5.14)

Number of Regular Clients (at time of

background survey)

(1.07)

Marital Status

$\begin{array}{rr}\text { Widowed } & 0.23 \\ \text { Divorced / Separated } & 0.20 \\ \text { Cohabitating } & 0.13 \\ \text { Never Married / Not Cohabitating } & 0.44\end{array}$

Has working as a CSW changed likelihood of marrying?

Yes, made it more likely $\quad 0.41$

Yes, made it less likely $\quad 0.03$

No change $\quad 0.57$

Tribe

$\begin{array}{rr}\text { Luhya } & 0.39 \\ \text { Luo } & 0.51 \\ \text { Other } & 0.11\end{array}$

$\begin{array}{ll}\text { Respondent is in a peer group } & 0.44\end{array}$

$\begin{array}{ll}\text { Respondent has outside job } & 0.84\end{array}$

Panel B. HIV Knowledge

Tested for HIV

0.60

HIV Knowledge Test Score (0-1 scale) 0.94

(0.06)

Panel C. Access to Savings

Has Savings Account

Savings Withdrawn in Past Month

72.82

(for women with savings accounts)

(430.27)

Participates in ROSCA

0.64

Observations

192

Notes: In Panel A, the Cohabitating category for marital status includes women that have never been married. Monetary values in Kenyan shillings. Exchange rate was roughly 70 Kenyan shillings / \$1 US during study period. Standard deviations in parentheses. 
Table 2. Summary Statistics from Diaries: Shocks, Transfers, Expenditures, and Savings

\begin{tabular}{|c|c|c|c|}
\hline Panel A. Shocks & $\begin{array}{c}(1) \\
\text { Daily Average }\end{array}$ & $\begin{array}{c}(2) \\
\text { Occurred at Least } \\
\text { Once over } 3 \text { Month } \\
\text { Sample Period }\end{array}$ & \\
\hline Someone in Household Sick (other than respondent) & 0.37 & 0.93 & \\
\hline Respondent Sick & 0.34 & 0.98 & \\
\hline Respondent had STI & 0.03 & 0.34 & \\
\hline Observations & 12386 & 209 & \\
\hline IDs & 192 & 192 & \\
\hline Panel B. Transfers \& Gifts from Clients (Daily Averages) & $\begin{array}{c}(1) \\
\text { Sending Out }\end{array}$ & $\begin{array}{c}\text { (2) } \\
\text { Receiving From }\end{array}$ & $\begin{array}{c}(3) \\
\text { Net Flow }\end{array}$ \\
\hline Loan and Gift Flows from Family \& Friends & $\begin{array}{c}32.32 \\
(143.83)\end{array}$ & $\begin{array}{c}54.90 \\
(206.58)\end{array}$ & $\begin{array}{c}-22.49 \\
(245.95)\end{array}$ \\
\hline Gifts received from Regular Clients & $\begin{array}{c}90.39 \\
(286.47)\end{array}$ & & \\
\hline Observations & 12372 & & \\
\hline Panel C. Expenditures (Daily Averages) & (1) & & \\
\hline Total Expenditures & $\begin{array}{c}655.00 \\
(681.41)\end{array}$ & & \\
\hline Food Expenditures & $\begin{array}{c}148.44 \\
(153.01)\end{array}$ & & \\
\hline Observations & 12427 & & \\
\hline IDs & 192 & & \\
\hline
\end{tabular}

Note: Sickness is an indicator variable equal to 1 if household or respondent reported having a cough, fever, malaria, typhoid, diarrhea, cuts or burns, or any other illness. There are more observations than IDs in Column 2 of Panel A because some women were sampled in both rounds.

All monetary values in Kenyan shillings (Ksh). The exchange rate over the data collection period was approximately $70 \mathrm{Ksh} /$ \$1 US. Means are reported, with standard deviations in parentheses. Exact number of observations differ for some variables, due to reporting errors. 


\begin{tabular}{|c|c|c|c|c|}
\hline Panel A. Averages & $\begin{array}{c}(1) \\
\text { Daily Average }\end{array}$ & $\begin{array}{c}(2) \\
\text { Transaction Data: } \\
\text { All Clients } \\
\end{array}$ & $\begin{array}{c}(3) \\
\text { Transaction Data: } \\
\text { Regulars Only } \\
\end{array}$ & $\begin{array}{c}(4) \\
\text { Transaction Data: } \\
\text { Casuals Only } \\
\end{array}$ \\
\hline Participated in the Sex Sector & 0.76 & & & \\
\hline Income from Sex Work & $\begin{array}{l}682.45 \\
(746.26)\end{array}$ & & & \\
\hline Total Income (All Sources) & $\begin{array}{l}784.19 \\
(775.97)\end{array}$ & & & \\
\hline Number of Clients Seen & $\begin{array}{c}1.52 \\
(1.12)\end{array}$ & & & \\
\hline Number of Regular Clients Seen & $\begin{array}{l}0.54 \\
(0.66)\end{array}$ & & & \\
\hline Had Vaginal Sex & 0.74 & 0.95 & 0.96 & 0.94 \\
\hline Had Anal Sex & 0.22 & 0.23 & 0.19 & 0.26 \\
\hline Had Oral Sex & 0.19 & 0.19 & 0.17 & 0.21 \\
\hline Had Unprotected Vaginal or Anal Sex & 0.18 & 0.16 & 0.21 & 0.14 \\
\hline \# Times Unprotected Vaginal or Anal Sex & 0.42 & 0.27 & 0.40 & 0.20 \\
\hline \multicolumn{5}{|c|}{ Panel B. Occurred at Least Once During Sample Period } \\
\hline Vaginal Sex & 1.00 & & & \\
\hline Anal Sex & 0.82 & & & \\
\hline Oral Sex & 0.71 & & & \\
\hline Unprotected Vaginal or Anal Sex & 0.70 & & & \\
\hline Observations & 12432 & 18894 & 6697 & 12022 \\
\hline
\end{tabular}

Note: Figures are calculated from self-reported daily diary data. In Panels $A$ and $B$, the figures in Column 1 are daily averages. Figures in Columns 2-4 are averages across all transactions (up to a maximum of 3 client transactions per woman per day). The number of observations in Columns 3 and 4 do not sum to the total in Column 2 due to reporting errors. There are 192 total women in the sample, 108 of whom participated in Round 2. 
Table 4. Hedonic Price Regressions

\begin{tabular}{|c|c|c|c|c|c|c|}
\hline & (1) & \multirow[t]{2}{*}{$\overline{~(2) ~}$} & $\overline{(3)}$ & \multirow{2}{*}{\multicolumn{3}{|c|}{$\begin{array}{cc}(4) & (5) \\
-\end{array}$}} \\
\hline & & & & & & \\
\hline & All Clients & Regular Clients & Casual Clients & All Clients & All Clients & All Clients \\
\hline \multirow[t]{2}{*}{ Vaginal Sex } & 18.511 & 37.420 & 12.676 & 64.287 & 42.033 & 29.754 \\
\hline & (25.438) & (37.016) & $(25.254)$ & $(45.019)$ & $(45.464)$ & (56.269) \\
\hline \multirow[t]{2}{*}{ Anal Sex } & 73.868 & 60.718 & 65.116 & 167.886 & 84.519 & 81.095 \\
\hline & $(21.091)^{\star * *}$ & $(25.571)^{\star *}$ & $(21.908)^{\star \star *}$ & $(50.758)^{\star \star \star}$ & $(42.732)^{*}$ & $(39.060)^{* *}$ \\
\hline \multirow[t]{2}{*}{ Oral Sex } & 22.357 & 43.655 & 8.097 & 75.083 & 71.009 & 97.559 \\
\hline & $(14.604)$ & $(24.543)^{*}$ & $(13.931)$ & $(24.615)^{\star * \star}$ & $(34.515)^{\star *}$ & $(41.039)^{* *}$ \\
\hline \multirow{2}{*}{ Massage } & 59.563 & 63.119 & 46.667 & 53.521 & 18.729 & 18.177 \\
\hline & $(13.940)^{* * *}$ & $(19.504)^{\star \star \star}$ & $(14.368)^{\star \star \star}$ & $(24.821)^{\star \star}$ & (28.026) & $(26.224)$ \\
\hline \multirow[t]{2}{*}{ Kissing } & 49.169 & 51.250 & 39.573 & 50.141 & 32.634 & 41.127 \\
\hline & $(11.684)^{\star \star \star}$ & $(20.771)^{\star *}$ & $(9.702)^{\star \star \star}$ & $(25.947)^{*}$ & (29.186) & $(26.676)$ \\
\hline \multirow[t]{2}{*}{ Manual Stimulation } & 43.359 & 67.799 & 27.776 & 87.313 & 61.714 & 55.671 \\
\hline & $(15.283)^{\star \star \star}$ & $(26.643)^{\star *}$ & $(14.616)^{*}$ & $(25.405)^{\star * \star}$ & $(32.346)^{*}$ & (40.989) \\
\hline \multirow[t]{2}{*}{ Company } & 69.130 & 46.823 & 58.745 & 81.660 & 44.485 & 29.287 \\
\hline & $(13.011)^{\star \star *}$ & $(17.751)^{\star \star \star}$ & $(13.296)^{\star \star \star}$ & $(23.883)^{\star \star \star}$ & $(28.732)$ & $(22.778)$ \\
\hline \multirow[t]{2}{*}{ Stripping } & 39.476 & 30.917 & 34.479 & 48.728 & 25.385 & 39.515 \\
\hline & $(11.078)^{\star \star \star}$ & $(15.215)^{\star *}$ & $(11.650)^{\star \star \star}$ & $(18.987)^{\star \star}$ & (23.903) & $(25.054)$ \\
\hline \multirow[t]{2}{*}{ Sex in Thighs } & 35.699 & 18.974 & 51.699 & 67.973 & 113.480 & 72.131 \\
\hline & $(14.954)^{* \star}$ & $(21.922)$ & $(18.173)^{\star \star \star}$ & $(35.477)^{*}$ & $(51.423)^{\star *}$ & (60.153) \\
\hline \multirow[t]{2}{*}{ Other Activities } & 52.696 & 83.112 & 38.713 & 24.521 & 49.440 & 23.888 \\
\hline & $(27.867)^{*}$ & $(45.234)^{*}$ & $(24.828)$ & (38.497) & $(51.141)$ & (37.718) \\
\hline \multirow[t]{2}{*}{ Regular Client } & -18.770 & & & -30.481 & -13.916 & 7.889 \\
\hline & $(14.702)$ & & & $(25.816)$ & (25.999) & $(32.661)$ \\
\hline \multirow[t]{2}{*}{ Had Unprotected Sex } & 37.918 & 78.224 & 21.385 & 39.203 & 26.081 & 17.674 \\
\hline & $(16.322)^{\star *}$ & $(20.174)^{\star \star *}$ & (19.866) & $(31.281)$ & $(26.325)$ & $(34.546)$ \\
\hline \multirow[t]{2}{*}{ Client is Circumcised } & & & & & -27.989 & -21.315 \\
\hline & & & & & (20.838) & (23.967) \\
\hline \multirow[t]{2}{*}{ Client is Very Wealthy } & & & & & 38.45 & 41.415 \\
\hline & & & & & (45.999) & $(52.721)$ \\
\hline \multirow[t]{2}{*}{ Client is Handsome } & & & & & -82.616 & -110.21 \\
\hline & & & & & $(45.220)^{*}$ & $(54.424)^{* *}$ \\
\hline $\begin{array}{l}\text { Sex Worker Believes Client is at } \\
\text { High Risk of HIV / AIDS }\end{array}$ & & & & & & $\begin{array}{c}4.552 \\
(29.286)\end{array}$ \\
\hline Client Controls & No & No & No & No & Yes & Yes \\
\hline Observations & 18676 & 6674 & 12002 & 7108 & 3869 & 2419 \\
\hline Number of women & 192 & 192 & 192 & 108 & 108 & 95 \\
\hline R-squared & 0.04 & 0.04 & 0.04 & 0.04 & 0.03 & 0.04 \\
\hline
\end{tabular}

Note: All regressions are fixed effects regressions with controls for the month and day of the week.

Clustered standard errors in parentheses.

All regressions include controls for the round of data collection. The dependent variable is Kenyan shillings.

The exchange rate was approximately 70 Kenyan shillings to $\$ 1$ US during the data collection period.

Regressions include controls for other responses to the questions "Is the client wealthy?" and "Is the client handsome," but the coefficients are omitted for space.

is handsome. Columns 5 and 6 also include controls for client tribe, occupation and cleanliness.

Averages prices paid by type of client: regular - 485 shillings; casual - 432 shillings; overall - 450 shillings.

${ }^{*}$ significant at $10 \% ;{ }^{* *}$ significant at $5 \%$; ${ }^{* *}$ significant at $1 \%$ 
Total Food \# of Meals Private

Medical

Non-Medical

Expend. Expend. Respondent Expend. Expend. Shared Expend.

Mean of Dependent Variable ${ }^{\wedge}$

571.94
142.97

2.80

65.50

13.33

340.84

Panel A. Household Sickness

Somebody in Household (other

than respondent) Sick

75.327

$(17.783)^{* * *}$

7.662

[0.132]

(6.381)

$-0.015$

11.206

18.372

$(3.471)^{\star \star *} \quad(3.363)^{\star \star *}$

(0.013)

$[0.171]$

[1.379]

$56.429 \quad-0.039$

[-0.005]

2.667

$(18.060)^{* * *}$

$(7.734)$

$-0.016$

$(3.761)$

[0.099]

$[-0.000]$

$(0.016)$

12194

192

5485

[-0.006]

[0.041]

26.349

$(3.163)^{\star * *}$

12015

Number of women

0.02

108

192

12175

192

[1.977]

12158

192

0.01

0.04

51.022

$(13.059)^{* * *}$

[0.150]

25.939

$(13.211)^{*}$

[0.076]

12155

192

0.02

Panel B. Sexually Transmitted Infection (STI)

\begin{tabular}{lcccccc}
\hline STI & 2.660 & 12.263 & 0.003 & -8.693 & 25.933 & -8.993 \\
& $(39.764)$ & $(26.242)$ & $(0.043)$ & $(7.449)$ & $(8.759)^{* * *}$ & $(27.426)$ \\
First Day After STI & {$[0.005]$} & {$[0.086]$} & {$[0.001]$} & {$[-0.133]$} & {$[1.946]$} & {$[-0.026]$} \\
& 150.029 & 32.830 & 0.059 & 42.477 & 27.399 & 72.358 \\
& $(80.120)^{\star}$ & $(32.957)$ & $(0.068)$ & $(19.426)^{\star *}$ & $(11.284)^{\star *}$ & $(59.901)$ \\
Observations & {$[0.262]$} & {$[0.230]$} & {$[0.021]$} & {$[0.648]$} & {$[2.056]$} & {$[0.212]$} \\
Number of women & 10245 & 4446 & 10094 & 10227 & 10213 & 10210 \\
R-squared & 192 & 108 & 192 & 192 & 192 & 192 \\
\hline Note: All & 0.01 & 0.01 & 0.01 & 0.01 & 0.01 & 0.02 \\
\hline
\end{tabular}

Note: All regressions are fixed effects regressions with controls for the month and for the day of the week.

Clustered standard errors in parentheses.

All regressions include controls for the round of data collection.

${ }^{\wedge}$ Means of dependent variables are means when all shocks are equal to 0 .

Private expenditures include alcohol, soda, cigarettes, meals in restaurants, clothing, health and beauty products, and other privately consumed categories such as airtime for cellular phones.

${ }^{*}$ significant at $10 \%$; ${ }^{* *}$ significant at $5 \%$; ${ }^{* * *}$ significant at $1 \%$ 
Table 6. Labor Supply Response to Health Shocks

\begin{tabular}{|c|c|c|c|c|c|c|c|}
\hline & $\begin{array}{c}(1) \\
\text { Saw Any } \\
\text { Clients }\end{array}$ & $\begin{array}{c}(2) \\
\text { \# of Clients }\end{array}$ & $\begin{array}{c}(3) \\
\text { \# of Regular } \\
\text { Clients }\end{array}$ & $\begin{array}{c}(4) \\
\text { \# of Casual } \\
\text { Clients }\end{array}$ & $\begin{array}{c}(5) \\
\text { Sex Work } \\
\text { Income }\end{array}$ & $\begin{array}{c}6) \\
\text { Other } \\
\text { Income }\end{array}$ & $\begin{array}{c}7) \\
\text { Total } \\
\text { Income }\end{array}$ \\
\hline Mean of Dependent Variable ${ }^{\wedge}$ & 0.837 & 1.622 & 0.600 & 1.009 & 711.849 & 89.351 & 801.200 \\
\hline \multicolumn{8}{|l|}{ Panel A. Household Sickness } \\
\hline \multirow{3}{*}{$\begin{array}{l}\text { Somebody in Household } \\
\text { (other than respondent) Sick }\end{array}$} & 0.027 & 0.077 & 0.002 & 0.073 & 55.051 & 5.176 & 60.226 \\
\hline & $(0.013)^{\star \star}$ & $(0.035)^{\star *}$ & (0.019) & $(0.029)^{\star *}$ & $(20.026)^{\star * \star}$ & (5.910) & $(20.252)^{\star \star *}$ \\
\hline & {$[0.032]$} & {$[0.047]$} & {$[0.003]$} & {$[0.072]$} & {$[0.077]$} & {$[0.058]$} & {$[0.075]$} \\
\hline \multirow[t]{3}{*}{ Respondent Sick } & -0.081 & -0.165 & -0.044 & -0.119 & -100.114 & -2.655 & -102.768 \\
\hline & $(0.018)^{\star \star \star}$ & $(0.044)^{\star \star \star}$ & $(0.023)^{\star}$ & $(0.031)^{\star \star \star}$ & $(22.595)^{\star \star \star}$ & $(4.913)$ & $(22.701)^{\star * *}$ \\
\hline & {$[-0.097]$} & {$[-0.102]$} & {$[-0.073]$} & {$[-0.118]$} & {$[-0.141]$} & {$[-0.030]$} & {$[-0.128]$} \\
\hline Observations & 12199 & 12199 & 12199 & 12199 & 12199 & 12199 & 12199 \\
\hline Number of women & 192 & 192 & 192 & 192 & 192 & 192 & 192 \\
\hline R-squared & 0.01 & 0.03 & 0.01 & 0.04 & 0.02 & 0.01 & 0.02 \\
\hline \multicolumn{8}{|c|}{ Panel B. Sexually Transmitted Infection (STI) } \\
\hline \multirow[t]{3}{*}{$\overline{\mathrm{STI}}$} & -0.222 & -0.410 & -0.068 & -0.351 & -146.817 & -30.593 & -177.410 \\
\hline & $(0.049)^{\star \star \star}$ & $(0.115)^{\star \star \star}$ & $(0.063)$ & $(0.081)^{\star \star \star}$ & $(61.893)^{\star \star}$ & $(8.991)^{\star \star \star}$ & $(65.309)^{\star \star *}$ \\
\hline & {$[-0.265]$} & {$[-0.253]$} & {$[-0.113]$} & {$[-0.348]$} & {$[-0.206]$} & {$[-0.342]$} & {$[-0.221]$} \\
\hline \multirow[t]{3}{*}{ First Day After STI } & 0.057 & 0.265 & 0.110 & 0.151 & 232.913 & -26.432 & 206.482 \\
\hline & $(0.042)$ & $(0.091)^{\star \star \star}$ & $(0.056)^{*}$ & $(0.088)^{\star}$ & $(86.859)^{\star \star \star}$ & $(13.457)^{\star}$ & $(87.513)^{\star \star}$ \\
\hline & [0.068] & {$[0.163]$} & {$[0.183]$} & {$[0.150]$} & {$[0.327]$} & {$[-0.296]$} & {$[0.258]$} \\
\hline Observations & 10247 & 10247 & 10247 & 10247 & 10247 & 10247 & 10247 \\
\hline Number of women & 192 & 192 & 192 & 192 & 192 & 192 & 192 \\
\hline R-squared & 0.02 & 0.04 & 0.01 & 0.04 & 0.01 & 0.01 & 0.01 \\
\hline
\end{tabular}

Note: All regressions are fixed effects regressions with controls for the month and for the day of the week.

Clustered standard errors in parentheses. All regressions include controls for the round of data collection.

Sickness is an indicator variable equal to 1 if respondent reports a cough, fever, malaria, typhoid, diarrhea, cuts, burns, or other illnesses.

^Means of dependent variables are means when all shocks are equal to 0.

${ }^{*}$ significant at $10 \% ;{ }^{* *}$ significant at $5 \% ;{ }^{* * *}$ significant at $1 \%$ 
Table 7. Health Shocks and the Supply of Unprotected Sex

\begin{tabular}{|c|c|c|c|c|c|}
\hline & $\begin{array}{c}(1) \\
\text { Had Unprotected } \\
\text { Sex }\end{array}$ & $\begin{array}{c}(2) \\
\text { \# Unprotected } \\
\text { Sex Acts }\end{array}$ & $\begin{array}{c}(3) \\
\text { Had Anal } \\
\text { Sex }\end{array}$ & $\begin{array}{c}(4) \\
\text { Had Vaginal } \\
\text { Sex }\end{array}$ & $\begin{array}{c}(5) \\
\text { Had Oral } \\
\text { Sex }\end{array}$ \\
\hline Mean of Dependent Variable ${ }^{\wedge}$ & 0.156 & 0.342 & 0.198 & 0.825 & 0.174 \\
\hline \multicolumn{6}{|l|}{ Panel A. Household Sickness } \\
\hline \multirow{3}{*}{$\begin{array}{l}\text { Somebody in Household } \\
\text { (other than respondent) Sick }\end{array}$} & 0.032 & 0.068 & 0.043 & 0.023 & 0.037 \\
\hline & $(0.012)^{\star *}$ & $(0.041)$ & $(0.012)^{\star \star *}$ & $(0.013)^{*}$ & $(0.013)^{\star * *}$ \\
\hline & {$[0.206]$} & [0.199] & {$[0.217]$} & {$[0.028]$} & {$[0.213]$} \\
\hline \multirow[t]{3}{*}{ Respondent Sick } & -0.003 & -0.016 & -0.016 & -0.084 & -0.010 \\
\hline & $(0.011)$ & $(0.030)$ & $(0.013)$ & $(0.018)^{\star * *}$ & $(0.012)$ \\
\hline & {$[-0.019]$} & {$[-0.047]$} & {$[-0.081]$} & {$[-0.102]$} & {$[-0.058]$} \\
\hline Observations & 12199 & 11981 & 12199 & 12199 & 12199 \\
\hline Number of women & 192 & 192 & 192 & 192 & 192 \\
\hline R-squared & 0.02 & 0.01 & 0.02 & 0.01 & 0.02 \\
\hline \multicolumn{6}{|c|}{ Panel B. Sexually Transmitted Infection (STI) } \\
\hline \multirow[t]{3}{*}{ STI } & 0.018 & -0.037 & -0.063 & -0.229 & -0.013 \\
\hline & $(0.035)$ & $(0.094)$ & $(0.036)^{*}$ & $(0.047)^{\star \star \star}$ & $(0.030)$ \\
\hline & {$[0.116]$} & {$[-0.108]$} & {$[-0.318]$} & {$[-0.277]$} & {$[-0.075]$} \\
\hline \multirow[t]{3}{*}{ First Day After STI } & 0.085 & 0.170 & -0.023 & 0.071 & 0.055 \\
\hline & $(0.063)$ & $(0.137)$ & $(0.053)$ & $(0.044)$ & $(0.044)$ \\
\hline & {$[0.546]$} & {$[0.497]$} & {$[-0.116]$} & {$[0.086]$} & {$[0.316]$} \\
\hline Observations & 10247 & 10099 & 10247 & 10247 & 10247 \\
\hline Number of women & 192 & 192 & 192 & 192 & 192 \\
\hline R-squared & 0.02 & 0.01 & 0.02 & 0.02 & 0.02 \\
\hline
\end{tabular}

Note: All regressions are fixed effects regressions with controls for the month and for the day of the week.

Clustered standard errors in parentheses. All regressions include controls for the round of data collection.

Sickness is an indicator variable equal to 1 if respondent reports a cough, fever, malaria, typhoid, diarrhea, cuts, burns, or other illnesses. Unprotected sex includes unprotected anal and unprotected vaginal sex.

${ }^{\wedge} M e a n s$ of dependent variables are means when all shocks are equal to 0 .

* significant at 10\%; ${ }^{* *}$ significant at $5 \%$; ${ }^{* * *}$ significant at $1 \%$ 
Table 8. Health Shocks, Income, and Transactional Sex

\begin{tabular}{|c|c|c|c|c|c|}
\hline Panel A. Participation in Sex Sector & $\begin{array}{c}(1) \\
\text { Saw Any } \\
\text { Clients } \\
\end{array}$ & $\begin{array}{c}(2) \\
\# \text { of Clients }\end{array}$ & $\begin{array}{c}(3) \\
\text { \# of Regular } \\
\text { Clients }\end{array}$ & $\begin{array}{c}(4) \\
\text { \# of Casual } \\
\text { Clients }\end{array}$ & $\begin{array}{c}\text { (5) } \\
\text { Sex Work } \\
\text { Income }\end{array}$ \\
\hline Somebody in Household (other than respondent ) Sick & $\begin{array}{l}-0.003 \\
(0.017)\end{array}$ & $\begin{array}{l}-0.021 \\
(0.048)\end{array}$ & $\begin{array}{l}-0.014 \\
(0.027)\end{array}$ & $\begin{array}{l}-0.010 \\
(0.041)\end{array}$ & $\begin{array}{c}38.319 \\
(34.004)\end{array}$ \\
\hline $\begin{array}{l}\text { Somebody in Household Sick * Mean Daily Income } \\
\text { below Median of all CSWs }\end{array}$ & $\begin{array}{c}0.062 \\
(0.025)^{* *}\end{array}$ & $\begin{array}{c}0.202 \\
(0.069)^{\star * *}\end{array}$ & $\begin{array}{c}0.033 \\
(0.039)\end{array}$ & $\begin{array}{c}0.171 \\
(0.062)^{\star \star *}\end{array}$ & $\begin{array}{c}34.528 \\
(41.211)\end{array}$ \\
\hline Respondent Sick & $\begin{array}{c}-0.082 \\
(0.018)^{\star \star *}\end{array}$ & $\begin{array}{c}-0.165 \\
(0.043)^{\star * *}\end{array}$ & $\begin{array}{c}-0.044 \\
(0.023)^{*}\end{array}$ & $(0.030)^{\star \star *}$ & $\begin{array}{l}-100.276 \\
(22.668)^{\star \star \star}\end{array}$ \\
\hline Observations & 12199 & 12199 & 12199 & 12199 & 12199 \\
\hline Number of women & 192 & 192 & 192 & 192 & 192 \\
\hline R-squared & 0.01 & 0.04 & 0.01 & 0.04 & 0.02 \\
\hline Panel B. Sexual Activities & $\begin{array}{c}\text { (1) } \\
\text { Had Unprotected } \\
\text { Sex }\end{array}$ & $\begin{array}{c}(2) \\
\text { \# Unprotected } \\
\text { Sex }\end{array}$ & $\begin{array}{c}\text { (3) } \\
\text { Had Vaginal } \\
\text { Sex }\end{array}$ & $\begin{array}{l}(4) \\
\text { Had Anal } \\
\text { Sex }\end{array}$ & $\begin{array}{l}(5) \\
\text { Had Oral } \\
\text { Sex }\end{array}$ \\
\hline Somebody in Household (other than respondent ) Sick & $\begin{array}{c}0.019 \\
(0.015)\end{array}$ & $\begin{array}{c}0.043 \\
(0.057)\end{array}$ & $\begin{array}{l}-0.008 \\
(0.018)\end{array}$ & $\begin{array}{c}0.031 \\
(0.017)^{*}\end{array}$ & $\begin{array}{c}0.027 \\
(0.016)^{*}\end{array}$ \\
\hline $\begin{array}{l}\text { Somebody in Household Sick * Mean Daily Income } \\
\text { below Median of all CSWs }\end{array}$ & $\begin{array}{c}0.026 \\
(0.026)\end{array}$ & $\begin{array}{c}0.051 \\
(0.084)\end{array}$ & $\begin{array}{c}0.064 \\
(0.026)^{\star *}\end{array}$ & $\begin{array}{c}0.024 \\
(0.025)\end{array}$ & $\begin{array}{c}0.022 \\
(0.023)\end{array}$ \\
\hline Respondent Sick & $\begin{array}{l}-0.003 \\
(0.011)\end{array}$ & $\begin{array}{l}-0.016 \\
(0.030)\end{array}$ & $\begin{array}{c}-0.085 \\
(0.018)^{\star \star \star}\end{array}$ & $\begin{array}{c}-0.016 \\
(0.013)\end{array}$ & $\begin{array}{l}-0.010 \\
(0.012)\end{array}$ \\
\hline Observations & 12199 & 11981 & 12199 & 12199 & 12199 \\
\hline Number of women & 192 & 192 & 192 & 192 & 192 \\
\hline R-squared & 0.02 & 0.01 & 0.01 & 0.02 & 0.02 \\
\hline
\end{tabular}

Note: All regressions are fixed effects regressions with controls for the month and for the day of the week.

Clustered standard errors in parentheses. All regressions include controls for the round of data collection.

Panels include controls for own sickness though the coefficients are not reported.

Percentile of income distribution: minimum - $153 \mathrm{Ksh}$; 25th - 509 Ksh; 50 th - 766 Ksh; 75th - 1,089 Ksh; maximum - 2,068 Ksh.

${ }^{*}$ significant at 10\%; ${ }^{* *}$ significant at $5 \%$; ${ }^{* * *}$ significant at $1 \%$ 
Table 9. Expected Difference in the Probability of HIV Infection Over Time

\begin{tabular}{lcccc}
\hline \hline & $\begin{array}{c}(1) \\
\text { Perfect Consumption } \\
\text { Smoothing }\end{array}$ & $\begin{array}{c}(2) \\
\text { Average Woman } \\
\text { in Sample }\end{array}$ & $\begin{array}{c}(3) \\
\text { Difference }\end{array}$ & $\begin{array}{c}(4) \\
\text { Percentage } \\
\text { Difference }\end{array}$ \\
\hline $\begin{array}{l}\text { Estimated Probability of HIV Infection after: } \\
\text { 1 year }\end{array}$ & 0.031 & 0.033 & 0.002 & 0.071 \\
2 years & 0.061 & 0.065 & 0.004 & 0.070 \\
3 years & 0.090 & 0.096 & 0.006 & 0.068 \\
4 years & 0.118 & 0.125 & 0.008 & 0.067 \\
5 years & 0.145 & 0.154 & 0.010 & 0.066 \\
10 years & 0.268 & 0.285 & 0.016 & 0.061 \\
20 years & 0.465 & 0.488 & 0.024 & 0.051 \\
\hline
\end{tabular}

Note: Calculation assumes that the average client has 0.25 probability of being infected with HIV and that the transmission probability per sex act is 0.001 .

The estimated number of unprotected sex acts is taken from Table 7.

We compute that a woman that is perfectly insured from health risk would have 125 unprotected sexual encounters per year, while the average woman in our sample would have 134 unprotected sexual encounters per year. 
Appendix Table 1. Risk Premium by Perceived HIV Status

\begin{tabular}{|c|c|c|}
\hline & $\begin{array}{l}\text { Likely Positive } \\
\text { (1) }\end{array}$ & $\begin{array}{c}\text { Others } \\
(2)\end{array}$ \\
\hline \multirow[t]{2}{*}{ Vaginal Sex } & 46.759 & 2.054 \\
\hline & $(47.935)$ & $(14.912)$ \\
\hline \multirow[t]{2}{*}{ Anal Sex } & 45.311 & 59.023 \\
\hline & $(30.648)$ & $(8.938)^{\star \star \star}$ \\
\hline \multirow[t]{2}{*}{ Oral Sex } & 76.991 & 15.805 \\
\hline & $(31.141)^{\star \star}$ & $(8.633)^{\star}$ \\
\hline \multirow[t]{2}{*}{ Massage } & 125.813 & 52.511 \\
\hline & $(28.102)^{\star \star \star}$ & $(7.659)^{\star \star *}$ \\
\hline \multirow[t]{2}{*}{ Kissing } & 10.251 & 46.857 \\
\hline & $(27.748)$ & $(6.777)^{\star \star *}$ \\
\hline \multirow[t]{2}{*}{ Manual Stimulation } & 72.123 & 38.869 \\
\hline & $(39.251)^{*}$ & $(9.498)^{\star * *}$ \\
\hline \multirow[t]{2}{*}{ Company } & 67.429 & 64.501 \\
\hline & $(22.934)^{\star \star \star}$ & $(6.553)^{\star * *}$ \\
\hline Stripping & 99.99 & 34.35 \\
\hline \multirow[t]{2}{*}{ Sex in Thighs } & 7.68 & 34.01 \\
\hline & $(51.195)$ & $(10.757)^{\star \star \star}$ \\
\hline \multirow[t]{2}{*}{ Other Activities } & 18.356 & 55.477 \\
\hline & (83.901) & $(18.040)^{* * *}$ \\
\hline \multirow[t]{2}{*}{ Regular Client } & -15.685 & -24.904 \\
\hline & $(20.868)$ & $(6.214)^{\star \star \star}$ \\
\hline \multirow[t]{2}{*}{ Had Unprotected Sex } & 18.493 & 44.35 \\
\hline & (37.339) & $(8.875)^{\star \star *}$ \\
\hline Observations & 1329 & 16968 \\
\hline Number of women & 13 & 174 \\
\hline R-squared & 0.11 & 0.04 \\
\hline \multicolumn{3}{|c|}{$\begin{array}{l}\text { Note: All regressions are fixed effects regressions with controls for the month and } \\
\text { the day of the week. Clustered standard errors in parentheses. All regressions include } \\
\text { controls for the round of data collection. The dependent variable is Kenyan shillings. }\end{array}$} \\
\hline \multicolumn{3}{|c|}{$\begin{array}{l}\text { The variable for likely being HIV positive equals } 1 \text { if the woman had previously taken an HIV test and } \\
\text { reported that she believed herself to have a greater than } 50 \% \text { chance of being HIV positive. }\end{array}$} \\
\hline \multicolumn{3}{|c|}{ Seven percent of women are coded as being likely to be HIV positive. } \\
\hline \multicolumn{3}{|c|}{ Client characteristics not included due to a lack of observations. } \\
\hline
\end{tabular}


Appendix Table 2. Health Shocks, Perceived HIV Status, and Transactional Sex

\begin{tabular}{|c|c|c|c|c|c|}
\hline Panel A. Participation in Sex Sector & $\begin{array}{c}(1) \\
\text { Saw Any } \\
\text { Clients }\end{array}$ & $\begin{array}{c}(2) \\
\text { \# of Clients }\end{array}$ & $\begin{array}{c}(3) \\
\text { \# of Regular } \\
\text { Clients }\end{array}$ & $\begin{array}{c}(4) \\
\text { \# of Casual } \\
\text { Clients }\end{array}$ & $\begin{array}{c}\text { (5) } \\
\text { Sex Work } \\
\text { Income }\end{array}$ \\
\hline \multirow[t]{2}{*}{ Somebody in Household (other than respondent ) Sick } & 0.017 & 0.058 & -0.007 & 0.063 & 61.142 \\
\hline & $(0.014)$ & $(0.038)$ & $(0.021)$ & $(0.032)^{* *}$ & $(21.468)^{\star \star \star}$ \\
\hline \multirow[t]{2}{*}{ Somebody in Household Sick * Likely HIV Positive } & 0.080 & 0.183 & 0.090 & 0.087 & -69.076 \\
\hline & $(0.041)^{*}$ & $(0.114)$ & $(0.073)$ & $(0.113)$ & $(79.672)$ \\
\hline \multirow[t]{2}{*}{ Respondent Sick } & -0.075 & -0.148 & -0.035 & -0.111 & -93.533 \\
\hline & $(0.017)^{* * *}$ & $(0.041)^{\star * \star}$ & $(0.022)$ & $(0.030)^{* * *}$ & $(22.214)^{\star * *}$ \\
\hline Observations & 11931 & 11931 & 11931 & 11931 & 11931 \\
\hline Number of id & 187 & 187 & 187 & 187 & 187 \\
\hline \multirow[t]{3}{*}{ R-squared } & 0.01 & 0.03 & 0.01 & 0.04 & 0.02 \\
\hline & (1) & $(2)$ & (3) & $(4)$ & (5) \\
\hline & Had Unprotected & \# Unprotected & Had Vaginal & Had Anal & Had Oral \\
\hline Panel B. Sexual Activities & Sex & Sex & Sex & Sex & Sex \\
\hline \multirow[t]{2}{*}{ Somebody in Household (other than respondent ) Sick } & 0.028 & 0.056 & 0.014 & 0.032 & 0.035 \\
\hline & $(0.014)^{\star *}$ & $(0.045)$ & $(0.014)$ & $(0.013)^{\star *}$ & $(0.013)^{\star * *}$ \\
\hline \multirow[t]{2}{*}{ Somebody in Household Sick * Likely HIV Positive } & 0.046 & 0.147 & 0.071 & 0.122 & 0.032 \\
\hline & $(0.046)$ & $(0.128)$ & $(0.045)$ & $(0.067)^{*}$ & $(0.033)$ \\
\hline \multirow[t]{2}{*}{ Respondent Sick } & 0.000 & -0.016 & -0.078 & -0.012 & -0.007 \\
\hline & $(0.011)$ & $(0.030)$ & $(0.018)^{\star * \star}$ & $(0.012)$ & $(0.012)$ \\
\hline Observations & 11931 & 11730 & 11931 & 11931 & 11931 \\
\hline Number of id & 187 & 187 & 187 & 187 & 187 \\
\hline R-squared & 0.02 & 0.01 & 0.01 & 0.02 & 0.02 \\
\hline
\end{tabular}

Note: All regressions are fixed effects regressions with controls for the month and the day of the week.

Clustered standard errors in parentheses. All regressions include controls for the round of data collection.

Sickness is an indicator variable equal to 1 if respondent reports a cough, fever, malaria, typhoid, diarrhea, cuts, burns, or other

illnesses. The variable for likely being HIV positive equals 1 if the woman had previously taken an HIV test and

reported that she believed herself to have a greater than $50 \%$ chance of being HIV positive.

${ }^{*}$ significant at 10\%; ** significant at $5 \%$; ${ }^{* * *}$ significant at $1 \%$ 